\title{
Latent Plasticity of Effector-like Exhausted CD8 T cells contributes to memory responses
}

Saravanan Raju, ${ }^{1} \dagger \mathrm{Yu}$ Xia, ${ }^{1} \dagger$ Bence Daniel, ${ }^{2}$ Kathryn E. Yost, ${ }^{2}$ Elliot Bradshaw, ${ }^{1}$ Elena Tonc, ${ }^{1}$

Daniel J. Verbaro, ${ }^{1}$ Ansuman T. Satpathy, ${ }^{2,3}$ Takeshi Egawa ${ }^{1 *}$

${ }^{1}$ Department of Pathology and Immunology, Washington University School of Medicine, Saint Louis, MO 63110, USA

${ }^{2}$ Department of Pathology, ${ }^{3}$ Parker Institute for Cancer Immunotherapy, Stanford University

School of Medicine, Stanford, CA 94305, USA

†These authors contributed equally

${ }^{4}$ Corresponding author: egawat@wustl.edu 


\begin{abstract}
Persistent antigen induces a dysfunctional CD8 T cell state known as T cell "exhaustion" characterized by expression of PD-1 and decreased effector functions. Nevertheless, dysfunctional CD8 T cells can mediate control of antigen burden which is long-lasting. While heterogeneity of exhausted CD8 T cells has been described, the cells which actively proliferate and exert viral control have remained elusive. Here, we define subsets of PD- $1^{+}$CD8 T cells during chronic infection marked by expression of CX3CR1 with substantial in situ proliferation and high expression of granzyme B. Moreover, these cells maintain the effector pool through self-renewal independently of previously defined stem-like cells. Unexpectedly, CX3CR1 ${ }^{+}$CD8 T cells retain plasticity to be reprogrammed to memory cells through expression of TCF-1 and re-gain polyfunctionality. Thus, we define a subset of effector-like exhausted CD8 T cells with capacity to contribute to the memory pool, offering a prime target for novel immunotherapies.
\end{abstract}




\section{Introduction}

Upon encountering antigen, naive CD8 T cells undergo robust clonal expansion and acquire effector functions for host protection against pathogens and tumors. However, in the context of persistent antigen exposure seen in chronic viral infections, they are subject to an alternative differentiation pathway known as T cell exhaustion, which is characterized by continued expression of inhibitory receptors, decreased cytokine secretion, and blunted proliferation $(1,2)$. Although the acquisition of this dysfunctional state serves as a protective host mechanism by which CD8 T cell-mediated tissue damage is restricted, this pathway facilitates persistence of infection or tumors (3-5). Nevertheless, exhausted CD8 T cells are not inert and can actively control antigen burden ( 6 ). Recent data have highlighted heterogeneity within exhausted CD8 T cells both at the population (7-10) and single-cell level (11-13). However, identification of a subset undergoing active proliferation with effector gene expression that directly impacts viral control is lacking. Thus, there is considerable interest in defining subpopulations of exhausted CD8 T cells and the developmental relationship between them, as such knowledge provides biomarkers for productive CD8 $\mathrm{T}$ cell responses as well as direct targets for future immunotherapies.

Our current understanding of exhausted CD8 T cells is based largely upon division of cells into two major subpopulations in viral infection and tumor models; cells marked with expression of the transcription factor TCF-1 $\left(\mathrm{CXCR}^{+}\right)$with stem-like characteristics and TCF$1^{-/ l o}$ Blimp- $1^{+}$TIM3 $^{+}$cells marked by a more severe exhaustion signature despite expression of effector genes such as granzyme B $(G z m b)(8-10)$. The TCF-1 ${ }^{+}$population comprises stem-like CD8 T cells that exhibit substantial proliferative capacity upon PD-1 blockade and is thus thought to continuously replenish the TIM3 cell pool during chronic infection or in tumors. 
However, these stem-like cells are largely quiescent under physiological conditions and it is thus unclear to what extent they undergo proliferation and actively contribute to replenishment of the effector CD8 T cell pool (12). Alternatively, it is possible, as seen in steady-state hematopoiesis (14-16), that the antigen-specific CD8 T cell pool is maintained mainly by intermediate precursors that actively self-renew to some extent and also give rise to differentiated effector cells, whereas stem-like cells only rarely transit to the more mature developmental stages. Yet, the identity of the proliferative subpopulation of CD8 T cells and their connection to the two major subpopulations aforementioned, is poorly understood.

In this work, we identified subpopulations of proliferating CD8 T cells that are marked by the expression of CX3CR1 and require CD4 T cell help, IL-21 and T-bet in the chronic LCMV infection model. Analogous CD8 subpopulations were also found in transplanted tumors. $\mathrm{CX} 3 \mathrm{CR} 1^{+}$cells emerge in parallel with $\mathrm{TCF}-1^{+}$and $\mathrm{TIM} 3^{+}$cells during the subacute phase of antiviral response, and their appearance is independent of the TCF- $1^{+}$population. Tamoxifeninducible fate-mapping revealed they are maintained by self-renewal, and they contribute little to the pool of terminally exhausted $\mathrm{TIM}^{+} \mathrm{CX} 3 \mathrm{CR} 1^{-} \mathrm{CD} 8 \mathrm{~T}$ cells. Unexpectedly, despite their acquisition of Blimp-1 together with loss of TCF-1 expression during antiviral response, $\mathrm{CX} 3 \mathrm{CR} 1^{+} \mathrm{PD}-1^{+} \mathrm{CD} 8 \mathrm{~T}$ cells become memory cells with renewed TCF-1 expression and proliferative capacity upon rechallenge. These results demonstrate early segregation of PD- $1^{+}$ CD8 T cells into distinct lineages analogous to effector memory, central memory and differentiated effectors during acute responses, and latent plasticity of exhausted CD8 T cells for their reprogramming to memory $\mathrm{T}$ cells. 


\section{Results}

\section{CX3CR1 defines a unique subset of exhausted non-TCF1 CD8 T cells that actively proliferate}

To investigate additional heterogeneity within exhausted CD8 T cells, we performed single cell RNA sequencing (scRNA-seq) of antigen-specific gp33-tetramer binding cells during the chronic phase of LCMV-c13 infection. UMAP projection of this dataset demonstrated 4 clusters of cells including the previously defined TCF $-1^{+}$and $\mathrm{TIM}^{+}$subsets (Fig. 1A, Fig. S1A). Two additional clusters were identified that were most notable for CX3CR1 expression. One of these CX3CR1 clusters was enriched for expression of genes encoding Tbx21 and Zeb2 while expression of Pdcd1, Eomes and Tox was low. The other CX3CR1 ${ }^{+}$cluster was marked with increased expression of inhibitory receptors Havcr2. Lag3 and Tigit, with a significant proportion of the cells positive for Mki67, encoding Ki-67 protein, suggesting active proliferation. We thus sought to better characterize these populations during chronic viral infection.

Consistent with the scRNA-seq data, approximately 40\% of LCMV-gp33-specific CD8 T cells in mice infected with LCMV-clone 13 (LCMV-c13) expressed CX3CR1, and its expression was seen exclusively in TCF-1-negative cells (Fig. 1B). The frequency of CX $3 \mathrm{CR} 1^{+}$cells was notable in TCF-1- $1^{-} \mathrm{TIM}^{-} \mathrm{CD} 8 \mathrm{~T}$ cells, a subpopulation of PD- $1^{+} \mathrm{CD} 8 \mathrm{~T}$ cells distinct from the previously characterized TCF $-1^{+}$and $\mathrm{TIM}^{+}$cells, and expressed CD44 at higher levels than $\mathrm{CX} \mathrm{CR} 1^{-}$cells in both $\mathrm{TIM}^{-}$and $\mathrm{TIM}^{+}$fractions (Fig. 1C).

To determine whether the $\mathrm{CX} 3 \mathrm{CR} 1^{+}$cells comprise proliferating CD8 T cells, we measured BrdU incorporation, which directly reflects DNA synthesis during the S-phase of the cell cycle, following pulse labeling in the chronic phase (22 dpi) of LCMV-c13 infection (Fig. 
1D). We confirmed the quiescence of $\mathrm{TCF}-1^{+}$cells as only $<5 \%$ of cells incorporated BrdU over 12-hours following one injection of BrdU. Among the TCF-1 ${ }^{-}$fractions, $\mathrm{BrdU}^{+}$cells were significantly enriched in the $\mathrm{CX} 3 \mathrm{CR} 1^{+}$populations with the $\mathrm{TIM}^{+} \mathrm{CX} 3 \mathrm{CR} 1^{+}$cells exhibiting by far the highest incorporation of any subset $(\sim 30 \%)$. Both $\mathrm{TIM}^{+} \mathrm{CX} 3 \mathrm{CR} 1^{-}$and $\mathrm{TIM}^{-} \mathrm{CX} 3 \mathrm{CR} 1^{+}$ cells incorporated BrdU at lower frequencies than $\mathrm{TIM}^{+} \mathrm{CX} 3 \mathrm{CR} 1^{+}$cells while $\mathrm{TIM}^{-}$ $\mathrm{CX} 3 \mathrm{CR} 1^{-}$cells were similarly quiescent as $\mathrm{TCF}-1^{+}$stem-like CD8 T cells. Consistent results were seen with Ki-67 staining, which is often used as a surrogate for cell cycle status (Fig. S1b,c). CD8 T cells in all the subpopulations expressed Ki-67 at similarly high frequencies during the subacute phase of antiviral response ( $8 \mathrm{dpi})$. In the chronic phase $(22 \mathrm{dpi})$, the majority of $\mathrm{TIM}^{+} \mathrm{CX} \mathrm{CR} 1^{+}$cells retained $\mathrm{Ki}-67$ expression at a higher level compared to all other populations. These results support the notion that not all $\mathrm{TIM}^{+}$cells lose proliferative capacity and are terminally exhausted (12), and importantly, that expression of CX3CR1 marks proliferating effector cells within $\mathrm{TIM}^{+}$cells.

The amount of PD-1 surface expression is known to correlate with the extent of exhaustion, with higher levels corresponding to more severe exhaustion and unresponsiveness to the checkpoint blockade $(7,17,18)$. Prior studies have demonstrated that TCF- $1^{+}$subset expresses lower amounts of PD-1 compared to $\mathrm{TIM}^{+}$cells, and is thus less exhausted with reserved proliferative potential. Among CD8 T cells in the five subpopulations, TIM3$\mathrm{CX} 3 \mathrm{CR} 1^{+}$cells expressed the lowest amounts of PD-1 compared to all other subsets, including TCF $-1^{+}$cells, previously shown to express lower amounts of PD- 1 compared to $\mathrm{TIM}^{+}$cells (Fig. 1E). $\mathrm{TIM}^{+} \mathrm{CX} 3 \mathrm{CR} 1^{-}$cells expressed the highest levels of PD-1, consistent with a more severely exhausted state. 
A critical aspect of $\mathrm{T}$ cell biology is egress of CD8 T cells from secondary lymphoid organs to peripheral blood and extravasation into tissue to mediate immunity. Effector cell subsets are typically found in both blood and tissue at higher frequencies compared to memorylike cells (19). To examine the migratory behavior of $\mathrm{CX} 3 \mathrm{CR} 1^{+}$cells, we performed in vivo labelling of T cells by an intravenous injection of anti-CD45.2 which allowed us to discriminate between tissue resident (CD45.2- $)$ and circulating $\left(\mathrm{CD} 45.2^{+}\right)$antigen-specific CD8 T cells present in lung. In contrast to $\mathrm{TIM}^{+} \mathrm{CX} 3 \mathrm{CR} 1^{-}$cells that were predominantly localized in the lung parenchyma, distribution of both $\mathrm{CX} 3 \mathrm{CR} 1^{+}$subpopulations was significantly enriched in the circulating compartment (Fig. S1D). Within the $\mathrm{CX} 3 \mathrm{CR} 1^{+}$populations, more $\mathrm{TIM}^{+}$cells were found in the tissues compared to $\mathrm{TIM}^{-}$cells, suggesting that $\mathrm{TIM}^{+} \mathrm{CX}^{-} \mathrm{CR} 1^{+}$cells preferentially migrate to the tissue, and proliferate upon antigen recognition.

We then asked whether analogous $\mathrm{CX} 3 \mathrm{CR} 1^{+} \mathrm{PD}-1^{+} \mathrm{CD} 8 \mathrm{~T}$ cells could be found in tumor-infiltrating lymphocytes (TILs) which are also exposed to chronic antigen stimulation. Indeed, when we analyzed TILs in MC38 and E.G7 tumors following subcutaneous inoculation we observed a fraction of PD $-1^{+}$cells that expressed CX3CR1 (Fig. S2A,B). These results highlight unique characteristics of $\mathrm{CX} 3 \mathrm{CR} 1^{+} \mathrm{PD}-1^{+} \mathrm{CD} 8 \mathrm{~T}$ cells, which are distinct from the previously characterized exhausted CD8 T cells in their proliferative activity and tissue distribution, and are present in both chronic infection and tumors.

\section{$C X 3 C R 1^{+} P D-1^{+}$CD8 $T$ cells comprise cells with active cell cycling and expression of effector} molecules

While scRNA-seq analysis allows characterization of novel cell populations, full transcriptome analysis is technically challenging due to low sequencing depth. To gain additional 
insight into the $\mathrm{CX} 3 \mathrm{CR} 1^{+}$populations of $\mathrm{CD} 8 \mathrm{~T}$ cells, we purified two subsets of $\mathrm{CX} 3 \mathrm{CR} 1^{+}$cells based on TIM3 expression as well as stem-like $\left(\mathrm{TCF}-1^{+}\right)$and terminally exhausted (TIM3 ${ }^{+}$ $\mathrm{CX} \mathrm{CR}^{-}{ }^{-}$) CD8 T cells for bulk RNA-seq on day 16 of LCMV infection. Unsupervised clustering and principal component analysis showed that $\mathrm{CX} 3 \mathrm{CR} 1^{+}$populations are transcriptomically distinct from $\mathrm{TCF}-1^{+}$stem-like cells and $\mathrm{TIM} 3^{+} \mathrm{CX} 3 \mathrm{CR} 1^{-} \mathrm{CD} 8 \mathrm{~T}$ cells $($ Fig. 2A and Fig. S3). Among genes encoding transcription factors, CX3CR $1^{+}$populations expressed high $T b \times 21$ and Zeb2, which cooperates with T-bet to regulate effector function of CD8 T cells as well as Prdm1 encoding BLIMP-1(20-22) (fig. 2B). A few factors that have been associated with memory CD8 T cells and stem-like PD- $1^{+}$CD8 T cells, including Tcf7, Id3 and Bcl6, were expressed at substantially lower levels by the $\mathrm{CX} 3 \mathrm{CR} 1^{+}$cells compared to the $\mathrm{TCF}-1^{+}$stem-like population (fig. 2B). Expression of genes associated with CD8 effector functions was also distinct between $\mathrm{TCF}-1^{+}$stem-like and $\mathrm{CX} 3 \mathrm{CR} 1^{+}$populations. Consistent with elevated $\mathrm{Tb} \times 21$ and Prdm1, expression of Ifng, Prf1, Gzma and Gzmb was higher in CX3CR1 ${ }^{+}$populations compared to $\mathrm{TCF}-1^{+}$cells although these genes were more highly expressed in $\mathrm{TIM}^{+}$than TIM3 $^{-}$populations at the population level (fig. 2B). Gene Set Enrichment Analysis (GSEA) also showed significant enrichment of genes associated with pathways for cell proliferation and $\mathrm{T}$ cell effector function in $\mathrm{TIM}^{+} \mathrm{CX} 3 \mathrm{CR} 1^{+}$cells compared to $\mathrm{TCF}-1^{+}$stem-like cells (fig. 2C). These results suggest that $\mathrm{TIM}^{+} \mathrm{CX} 3 \mathrm{CR} 1^{+}$cells are the most activated and proliferative effectors among the antigen-specific PD- $1^{+}$CD8 T cells.

We further examined amounts of proteins associated with CD8 T cell effector function. Consistent with the gene expression profiling data, expression of granzyme B (GZMB) by LCMV-specific CD8 T cells ex vivo was highest in the $\mathrm{TIM} 3^{+} \mathrm{CX} 3 \mathrm{CR} 1^{+}$cells among the PD- ${ }^{+}$ CD8 T cells (fig. 2D). Despite comparable $G z m b$ mRNA expression between $\mathrm{TIM}^{+} \mathrm{CX} 3 \mathrm{CR} 1^{+}$ 
cells and $\mathrm{TIM}^{+} \mathrm{CX} \mathrm{CR} 1^{-}$cells, GZMB protein was expressed at a higher frequency and level in $\mathrm{TIM}^{+} \mathrm{CX} 3 \mathrm{CR} 1^{+}$cells, further suggesting that they retain effector function as cytotoxic T cells. Furthermore, we profiled expression of the two E-box transcription factors T-bet and Eomes, which are partially redundant in the control of effector functions of CD8 T cells (23). While a previous study demonstrated that T-bet is necessary for the development of PD-1 $1^{\text {lo/int }}$ progenitorlike CD8 T cells, the nature of the T-bet ${ }^{\text {hi }}$ Eomes $^{\text {lo }} \mathrm{PD}-1^{\text {lo/in }}$ progenitor-like cells remains unknown since TCF-1 ${ }^{+}$stem-like CD8 T cells are Eomes ${ }^{\text {hi }}(8)$. Among the four TCF-1 ${ }^{-}$ subpopulations in the LCMV-specific CD8 T cells, TIM3 ${ }^{-} \mathrm{CX} 3 \mathrm{CR} 1^{+}$cells expressed significantly higher levels of T-bet followed by $\mathrm{TIM} 3^{+} \mathrm{CX} 3 \mathrm{CR} 1^{+}$cells (fig. 2E). In contrast, $\mathrm{TIM}^{+} \mathrm{CX}^{\mathrm{CR}} 1^{-}$cells were devoid of T-bet-expressing cells. These results indicate that $\mathrm{CX} 3 \mathrm{CR} 1^{+}$cells are enriched for cells with active effector functions, while $\mathrm{TIM}^{+}{ }^{+} \mathrm{CX} 3 \mathrm{CR} 1^{-}$cells are terminally exhausted.

\section{CD4 help mediated by $I L-21$ is required for exhausted $C X 3 C R 1^{+}$cells}

We next sought to determine what factors within the immune response promote the generation and/or maintenance of the $\mathrm{CX} 3 \mathrm{CR}^{+}$populations. It is well established that the absence of CD4 T cells in LCMV-c13 infection causes severe CD8 T cell exhaustion, allowing permanent persistence of virus (2). Severe CD8 T cell exhaustion was observed early in infection, when viral burden is still comparable between CD4 T cell-replete and -depleted conditions $(7,24)$. Considering this, we asked whether the progressive CD8 $\mathrm{T}$ cell exhaustion in the "helpless" context results from the defective development of CX3CR1 ${ }^{+} \mathrm{CD} 8 \mathrm{~T}$ cell populations. Indeed, in mice treated with anti-CD4 prior to infection with LCMV-c13, we observed an almost complete absence of CX3CR $1^{+}$cells in LCMV-specific, $\mathrm{PD}-1^{+} \mathrm{CD} 8 \mathrm{~T}$ cells 
3-4 weeks after infection (fig. 3A,B, fig. S4). Consistent with the enrichment of T-bet ${ }^{+}$cells in the $\mathrm{CX} 3 \mathrm{CR} 1^{+}$fractions, overall T-bet ${ }^{+}$cells in LCMV-gp33-specific CD8 T cells were severely reduced in CD4-depleted mice (fig. 3c). Analysis of CD4-depleted versus CD4-replete, LCMVc13-infected mice in the subacute period on 8 dpi showed relatively normal development of LCMV-specific CX3CR1 ${ }^{+}$CD8 T cells, including $\mathrm{TIM}^{+}$and $\mathrm{TIM}^{-}{ }^{-}$subpopulations (fig. 3A,B). On 15 dpi however, $\mathrm{TIM}^{-}{ }^{-} \mathrm{CX} 3 \mathrm{CR} 1^{+} \mathrm{CD} 8 \mathrm{~T}$ cells were substantially reduced while $\mathrm{TIM}^{+}$ $\mathrm{CX} 3 \mathrm{CR} 1^{+} \mathrm{CD} 8 \mathrm{~T}$ cells were less severely affected, followed by almost total loss of CX3CR $1^{+}$ CD8 $\mathrm{T}$ cells on 22 dpi. Despite the drastic reduction of $\mathrm{CX} 3 \mathrm{CR} 1^{+}$cells, the numbers of $\mathrm{TIM} 3^{+}$ CX3CR1 ${ }^{-}$cells were comparable between CD4-depleted and CD4-replete mice (fig. 3B). These results indicate that the presence of CD4 T cells is dispensable for the initial development but necessary for the maintenance of $\mathrm{TIM}^{-} \mathrm{CX} 3 \mathrm{CR} 1^{+} \mathrm{T}-\mathrm{bet}^{\mathrm{Hi}}$ cells, which may function as the precursor for $\mathrm{TIM}^{+} \mathrm{CX} 3 \mathrm{CR} 1^{+}$cells. Our results also suggest that the $\mathrm{TIM}^{+}{ }^{+} \mathrm{CX} 3 \mathrm{CR} 1^{-}$cells are maintained independently of $\mathrm{CX} 3 \mathrm{CR} 1^{+}$cells.

CD4 T cells enhance CD8 $\mathrm{T}$ cell responses by providing direct help to CD8 T cells through cytokine secretion and licensing of dendritic cells. Among molecules involved in CD4 T cell-mediated help, IL-21 is predominantly produced by CD4 T cells and required to sustain CD8 T cell responses to chronic LCMV infection (25-27). We thus determined whether IL-21 is necessary for the CD4 T cell-dependent maintenance of the $\mathrm{CX} 3 \mathrm{CR} 1^{+}$populations of PD- $1^{+} \mathrm{CD} 8$ T cells. On 35 dpi, we observed a significant reduction in CX3CR1-expressing PD- $1^{+}$CD8 T cells in $I l 21 r^{-1-}$ mice (fig. 3D, E, fig. S5A,B). Consistent with CD4 T cell-independent development (8), the absolute numbers of TCF-1 ${ }^{+}$stem-like CD8 T cells were comparable between $I l 21 r^{+/+}$and $I l 21 r^{-/-}$mice. However, TCF-1 ${ }^{-}$PD- $1^{+}$CD8 T cells were reduced by 3 -fold and this reduction was predominantly caused by the profound loss of CX3CR1 $1^{+}$cells (fig. 3D,E). 
These results suggest that CD4 T cell-derived IL-21 enhances the development or maintenance of $\mathrm{TIM}^{-} \mathrm{CX}^{-} \mathrm{CR} 1^{+}$cells, possibly through the induction of T-bet expression (28). Similarly to CD4 depleted mice, numbers of $\mathrm{TIM}^{+} \mathrm{CX} \mathrm{CR} 1^{-}$cells were comparable between $\mathrm{Il2} 1 r^{+/+}$and $I l 21 r^{-/-}$mice (fig. 3E), further suggesting that the maintenance of $\mathrm{TIM}^{+} \mathrm{CX} \mathrm{CR} 1^{-}$cells is independent of $\mathrm{CX} 3 \mathrm{CR} 1^{+}$populations. Although follicular helper $\mathrm{T}$ (Tfh) cells in germinal centers produce IL-21, we observed intact CX3CR1 ${ }^{+} \mathrm{PD}-1^{+} \mathrm{CD} 8 \mathrm{~T}$ cells in muMT $\left(\mathrm{Ighm}^{-/-}\right)$ mice lacking B cells (fig. S5C,D), suggesting that the production of IL-21 by CD4 T cells does not require $\mathrm{T}_{\mathrm{FH}}$ differentiation in the germinal center.

\section{CX3CR1 ${ }^{+}$expressing CD8 $T$ cells are uniquely dependent on $T$-bet}

Our gene expression profile highlighted a reciprocal expression of the two E-box proteins, T-bet and Eomes in distinct subpopulations of antigen-specific PD- ${ }^{+} \mathrm{CD} 8 \mathrm{~T}$ cells. To determine how dichotomous expression of T-bet and Eomes imprints a molecular program onto exhausted CD8 T cells, we infected mice in which Tbx21 or Eomes was deleted in CD8 T cells. During the chronic phase of LCMV infection (29 dpi), frequencies of total LCMV-specific CD8 T cells were reduced by 2.5 -fold in $\mathrm{CD} 8$-cre $T b \times 21^{\mathrm{F} / \mathrm{F}}$ mice (fig. 4A,B). This reduction of total antigen-specific CD8 T cells was attributed to marked reduction of $\mathrm{CX} 3 \mathrm{CR} 1^{+} \mathrm{CD} 8 \mathrm{~T}$ cells, most notably to $\mathrm{TIM}^{-} \mathrm{CX}^{-} \mathrm{CR} 1^{+}$that expressed the highest amounts of T-bet among all fractions (Figs. 2E, 4A,B). Notably, the reduction of TCF- $1^{+}$stem-like cells as well as $\mathrm{TIM}^{+} \mathrm{CX} 3 \mathrm{CR} 1^{-}$ cells was minimal, indicating that T-bet plays the crucial role in specifically programming the CX3CR $1^{+}$subpopulations of exhausted CD8 T cells (fig. 4A,B). To determine the impact of loss of $\mathrm{CX} 3 \mathrm{CR} 1^{+} \mathrm{CD} 8 \mathrm{~T}$ cells on viral control, we tracked LCMV-c13 infected CD8-cre $T b x 21^{\mathrm{F} / \mathrm{F}}$ and control $\operatorname{Tb} \times 21^{\mathrm{F} / \mathrm{F}}$ mice for 100 days, by which time the majority of immune-competent mice 
resolve viremia (fig. 4C). While WT mice were able to resolve viremia, T-bet-deficient mice still demonstrated significant viremia. These results indicate deletion of T-bet/Tbx21 specifically results in loss of $\mathrm{CX} 3 \mathrm{CR} 1^{+}$effector cells required for viral control. Importantly, while only representing a fraction of total antigen-specific $\mathrm{PD}-1^{+} \mathrm{CD} 8 \mathrm{~T}$ cells, this population is crucial for an overall productive CD8 $\mathrm{T}$ cell response.

In contrast to $\mathrm{T}$-bet expression being highest in $\mathrm{TIM}^{-} \mathrm{CX} 3 \mathrm{CR} 1^{+}$cells, Eomes was expressed more broadly in PD- $1^{+} \mathrm{CD} 8 \mathrm{~T}$ cells with its expression lowest in $\mathrm{TIM}^{-} \mathrm{CX} 3 \mathrm{CR} 1^{+}$ cells (fig. 2E). Deletion of Eomes in CD8 T cells resulted in increased frequencies and absolute numbers of total LCMV-gp33-specific CD8 T cells approximately by 3-fold (fig. 4D, E). This increase was most attributable to a marked increase in TCF- $1^{+}$stem-like CD8 T cells (fig. $\left.4 \mathbf{E}\right)$. In the $\mathrm{TCF}-1^{-}$fractions, however, we did not detect significant differences except for a $\sim 2.5$-fold increase in the numbers of $\mathrm{TIM}^{-}{ }^{-} \mathrm{CX} 3 \mathrm{CR}^{+} \mathrm{CD} 8 \mathrm{~T}$ cells, suggesting that Eomes functions as a negative regulator for mobilization of relatively quiescent CD8 T cells, including TCF- $1^{+}$and $\mathrm{TIM}^{-} \mathrm{CX}^{-} \mathrm{CR}^{+}$cells, to downstream proliferation and differentiation programs. Finally, Eomes in CD8 T cells was essential for control of chronic LCMV infection with viral persistence in $\mathrm{CD} 8$-cre Eomes $^{\mathrm{F} / \mathrm{F}}$ mice with the majority of CD8-cre Eomes $^{\mathrm{F} / \mathrm{F}}$ mice failing to resolve viremia on $\geq 100$ dpi (fig. 4F). These results together indicate non-redundant roles of the two E-box proteins, T-bet and Eomes, in CD8 T cell responses to persisting antigen, and a unique role for T-bet in the maintenance of CX3CR1 expressing cells. 
Adoptive transfer studies demonstrated that TCF- $1^{+}$stem-like CD8 T cells give rise to terminally differentiated $\mathrm{TIM}^{+}$cells $(8)$. However, it remains unknown whether $\mathrm{CX} 3 \mathrm{CR} 1^{+} \mathrm{T}$ cells are derived from $\mathrm{TCF}-1^{+}$cells as intermediate cells that eventually give rise to terminally differentiated cells, or they constitute a distinct lineage of CD8 cells that develop and is maintained through a unique pathway. To address this question, we first utilized mice in which differentiation of the $\mathrm{TCF}-1^{+}$population is defective. Among the transcription factors selectively expressed in the TCF-1 ${ }^{+}$stem-like CD8 T cells (fig. 2B), deletion of Bcl6 with CD8-cre in LCMV-c13 infection resulted in a substantial loss of the TCF-1 ${ }^{\text {hi }}$ population with a small fraction of TCF-1 $1^{-/ \text {lo }}$ TIM3$^{-}$cells remaining on 8 dpi (fig. S6A). However, expansion of gp33-specific CD8 T cells was minimally affected by the absence of $B c l 6$ with the absolute number of $\mathrm{CX} 3 \mathrm{CR}^{+}$cells as well as total LCMV-gp33-specific CD8 T cells unchanged or only marginally decreased in CD8-cre $\mathrm{Bcl}^{\mathrm{F} / \mathrm{F}}$ mice compared to control $\mathrm{Bcl} 6^{\mathrm{F} / \mathrm{F}}$ mice (fig. S6B). These results indicate that the initial differentiation of $\mathrm{CX} 3 \mathrm{CR} 1^{+}$populations is independent of $\mathrm{TCF}-1^{+}$stemlike cells.

To determine whether $\mathrm{CX} 3 \mathrm{CR} 1^{+} \mathrm{CD} 8 \mathrm{~T}$ cells are constitutively replenished by $\mathrm{CX} 3 \mathrm{CR} 1^{-}$ cells, presumably by $\mathrm{TCF}-1^{+}$stem-like cells, we fate-mapped $\mathrm{CX} 3 \mathrm{CR} 1^{+}$cells by utilizing the Cx3cr1-creERT2 allele crossed to the ROSA26-loxP-stop-loxP-tdTomato (R26tdT) reporter. One dose of tamoxifen (TAM) on 8 dpi was sufficient to label approximately $80 \%$ of CX3CR $1^{+} \mathrm{CD} 8$ $\mathrm{T}$ cells, which was examined by detection of td-Tomato (tdT) fluorescence in $\mathrm{CX} 3 \mathrm{CR} 1^{+} \mathrm{CD} 8 \mathrm{~T}$ cells in the peripheral blood two days after TAM administration (fig.5A, B, fig. S7A). Labelling was specific to $\mathrm{CX} 3 \mathrm{CR} 1^{+}$as minimal labelling of non-CX3CR1 expressing cells was observed following tamoxifen administration (fig. S7A,B). After a two-week chase period, we were surprised to see, the frequencies of $\mathrm{tdT}^{+}$cells in the $\mathrm{CX} 3 \mathrm{CR} 1^{+} \mathrm{CD} 8 \mathrm{~T}$ cells remained high with 
only a modest decay to $60 \%$ on $22 \mathrm{dpi}$ (fig. 5B). Frequencies of $\operatorname{tdT}^{+}$cells were the highest in the $\mathrm{TCF}^{-} 1^{-} \mathrm{TIM}^{-}{ }^{-} \mathrm{CX} 3 \mathrm{CR} 1^{+}$population followed by the $\mathrm{TIM} 3^{+} \mathrm{CX} 3 \mathrm{CR} 1^{+}$population, while the frequency of $\mathrm{TIM}^{+} \mathrm{CX} 3 \mathrm{CR} 1^{+}$cells was higher than that of $\mathrm{TIM} 3^{-} \mathrm{CX} 3 \mathrm{CR} 1^{+}$cells reflecting more active proliferation of $\mathrm{TIM}^{+} \mathrm{CX} 3 \mathrm{CR} 1^{+}$cells (fig. 5C,D). We also observed approximately $25 \%$ of $\operatorname{tdT}^{+}$cells showing the $\mathrm{TIM}^{+} \mathrm{CX}^{2} \mathrm{CR} 1^{-}$phenotype on $22 \mathrm{dpi}$ (fig. 5C). These results indicate that the $\mathrm{CX} 3 \mathrm{CR} 1^{+}$lineage is specified early after infection with minimal replenishment by $\mathrm{CX} 3 \mathrm{CR}^{-}$cells and although expression of CX3CR1 may be upregulated promiscuously by a fraction of antigen-specific CD8 $\mathrm{T}$ cells, $\mathrm{CX} 3 \mathrm{CR} 1^{+}$cells may retain some plasticity to be converted terminally exhausted $\mathrm{TIM}^{+} \mathrm{CX} 3 \mathrm{CR} 1^{-}$cells in the subacute phase.

When TAM was given in the chronic phase of anti-LCMV response on $22 \mathrm{dpi}$ and labeled cells were chased for 8 days, the vast majority of $\mathrm{tdT}^{+}$cells were found in the $\mathrm{CX} 3 \mathrm{CR} 1^{+}$ populations (fig. 5E, fig. S7B,C). Unlike the early labeling, $\operatorname{tdT}^{+}$cells were excluded from the $\mathrm{TCF} 1^{+}$and $\mathrm{TIM}^{+} \mathrm{CX}^{-} \mathrm{CR} 1^{-}$populations. Together with the results from the $\mathrm{TCF}-1^{+}$cellindependent formation of $\mathrm{CX} 3 \mathrm{CR} 1^{+}$cells in $\mathrm{Bcl} 6-\mathrm{CKO}$ mice and their active proliferative activity, these results indicate that $\mathrm{CX} 3 \mathrm{CR} 1^{+}$populations constitute a separate lineage which is distinct from $\mathrm{TCF}-1^{+}$and terminally differentiated $\mathrm{TIM}^{+}$cells and are maintained by selfrenewal.

\section{CX3CR1 ${ }^{+}$cells contribute to long-term memory CD8 T cells expressing TCF-1 after clearance}

\section{of infection}

In immune competent mice, infection of LCMV-c13 is eventually resolved by both $\mathrm{T}$ and B cell responses around 100 dpi (29-31). We next asked the long-term fate of CX3CR1 $1^{+}$cells following the clearance of LCMV-c13. Since it is technically difficult to study memory cell 
persistence following establishment of $\mathrm{T}$ cell exhaustion and antigen clearance in mouse tumor models, use of the LCMV model provides us with a unique opportunity to study long-term fate of CD8 T cells that have gone through exhausting conditions. To this goal, we administered TAM on 28 dpi, which allowed us to minimize the background labeling of $\mathrm{TCF}-1^{+} \mathrm{CD} 8 \mathrm{~T}$ cells, and chased the tdT-labeled cells for 100-120 days. Similar to acute LCMV infection, we were able to detect the persistence of LCMV-gp33-specific CD8 memory cells in the peripheral blood mononuclear cells and splenocytes of LCMV-c13-immune mice, although they retained low PD1 expression as reported (32) (fig. 6A, data not shown). In contrast to LCMV-Arm-immune mice, in which memory CD8 $\mathrm{T}$ cells were mostly $\mathrm{CD} 62 \mathrm{~L}^{+} \mathrm{TCF}-1^{+} \mathrm{CX} 3 \mathrm{CR} 1^{-}$central memory CD8 T cells, a substantial fraction of gp33-specific memory CD8 T cells in LCMV-c13-immune mice showed the effector-memory phenotype with expression of CX3CR1 (fig. 6A). TAM administration to LCMV-c13-infected Cx3cr1-creER fate-mapping mice on 28 dpi resulted in marking of $\sim 40 \%$ of LCMV-gp33-specific CD8 memory T cells on 100-120 dpi (fig. 6A,B). Almost all $\mathrm{tdT}^{+}$cells continued to express surface CX3CR1 and $\sim 40 \%$ of the $\mathrm{CX} 3 \mathrm{CR} 1^{+}$or $\mathrm{tdT}^{+}$ cells expressed the memory transcription factor TCF-1 (fig. 6A,B). The majority $(\sim 80 \%)$ of $\mathrm{CX} 3 \mathrm{CR} 1^{+}$memory CD8 $\mathrm{T}$ cells were also $\mathrm{tdT}^{+}$and thus were derived from $\mathrm{CX} 3 \mathrm{CR} 1^{+}$cells during the labeling period (fig. 6B). In contrast to PD- $1^{+}$CD8 T cells in the chronic phase, the $\mathrm{CX}_{3 \mathrm{CR}} 1^{+}$and $\mathrm{CX} 3 \mathrm{CR} 1^{-}$memory $\mathrm{CD} 8 \mathrm{~T}$ cells were able to produce IFN- $\gamma$ following stimulation with LCMV-gp33 or LCMV-gp276 peptide ex vivo (fig. 6C). Notably, approximately 50\% of $\mathrm{IFN}_{-} \mathrm{g}^{+}$cells also expressed TNF-a, indicating that the polyfunctionality was restored in these memory CD8 T cell populations (fig. 6C). Furthermore, both $\mathrm{CX} 3 \mathrm{CR} 1^{+}$and $\mathrm{CX} 3 \mathrm{CR} 1^{-}$memory CD8 T cells from LCMV-c13-immune mice were capable of secondary expansion following adoptive transfer to congenic WT mice followed by LCMV-Arm infection (fig. 6D). Since TCF- 
1 was substantially downregulated or not expressed by $\mathrm{CX} 3 \mathrm{CR} 1^{+}$cells during the chronic phase in the infected mice, and $C x 3 c r 1$-creER barely labelled the TCF $-1^{+}$cells when Tamoxifen was given in the chronic phase, these results indicated that the substantial fraction of TCF- $1^{+}$memory cells are converted from TCF-1 $1^{-} \mathrm{PD}-1^{+}$partially exhausted effector cells potentially through dedifferentiation. These results collectively indicate that CD8 T cells that fall into the exhausted state with downregulation of memory factors, TCF-1 and BCL6, and upregulation of BLIMP-1 in face of chronic antigen still retain plasticity to acquire the memory phenotype evidenced by long-term persistence and the capability of multiple cytokine production and secondary expansion. 


\section{Discussion}

The features of CD8 $\mathrm{T}$ cell responses to persistent antigen and mechanistic pathways to control pathogen and tumor burden are of great interest in the development of immunotherapies. CD8 T cells acquire an "exhausted" phenotype in the tumor microenvironment and during response to chronic viral infection (33). Recent studies have described heterogeneity of exhausted CD8 T cells in both humans and mouse models, and have identified a TCF-1 ${ }^{+}$stemlike population that retains proliferative potential and responds to immune checkpoint blockade targeting the PD-1/PD-L1 interaction $(8-10)$. These findings revealed the heterogeneity of exhausted CD8 T cells associated with their functionality and offer a potential explanation of why only a subset of cancer patients respond to anti-PD-1 therapy. However, subpopulations of exhausted CD8 T cells that are associated with ongoing immune responses have not been defined. Here we identify populations of exhausted CD8 T cells marked by expression of CX3CR1. These cells are endowed with significant proliferative activity, effector functions and capacity to control viral burden. While the $\mathrm{CX} 3 \mathrm{CR} 1^{+} \mathrm{CD} 8 \mathrm{~T}$ cells may be insufficient to eradicate tumors by themselves, the durable CD8 T cell response mediated by these cells can synergize with other immune components to enhance control of virus or tumors. The presence of these cells could thus be a biomarker for patients who respond well to immune checkpoint blockade, as suggested by a report with a small patient cohort (34).

Our data showed that the three major populations of PD $-1^{+} \mathrm{CD} 8 \mathrm{~T}$ cells, namely TCF-1 ${ }^{+}$ stem-like, $\mathrm{CX} 3 \mathrm{CR} 1^{+}$proliferative and $\mathrm{TIM}^{+} \mathrm{CX} 3 \mathrm{CR} 1^{-}$terminally differentiated/exhausted populations, are segregated early during antiviral responses and maintained independently of one another. This is reminiscent of the separation among terminal effectors, central memory and effector memory cells, which are also marked by CX3CR1 expression during acute responses, 
suggesting that analogous lineage commitment may take place in the persistent presence of antigen $(35,36)$. We observed the emergence of $\mathrm{CX} 3 \mathrm{CR} 1^{+}$cells in the subacute phase even in the absence of TCF $-1^{+}$cells or CD4 T cell help. Recent studies have described a similar population and concluded that $\mathrm{CX} 3 \mathrm{CR} 1^{+}$cells constitute a transitional population downstream of $\mathrm{TCF}-1^{+}$exhausted cells using adoptive transfer (37). It is likely that TCF-1 ${ }^{+}$cells retain potential to give rise to $\mathrm{CX} 3 \mathrm{CR} 1^{+}$cells as they generate $\mathrm{CX} 3 \mathrm{CR} 1^{+}$cells and terminally differentiated cells upon adoptive transfer or PD-1 blockade. However, the conversion from $\mathrm{TCF}-1^{+}$cells to $\mathrm{CX} 3 \mathrm{CR} 1^{+}$cells may only slowly occur during the chronic phase of antiviral response or in the tumor microenvironment without PD-1 blockade or adoptive transfer, given that we observe persistence of fate-mapped cells and active proliferation. Together with the slow conversion of Cx3crl fate-mapped cells to $\mathrm{TIM}^{+}{ }^{+} \mathrm{CX} 3 \mathrm{CR}^{-}$cells during the chronic phase, which was also reported by another recent paper $(38), \mathrm{CX} 3 \mathrm{CR} 1^{+}$cells could constitute an independent lineage that is sustainable by at least limited self-renewal (38).

Alternatively, it is possible that $\mathrm{CX} 3 \mathrm{CR} 1^{+}$cells require input from $\mathrm{TCF}-1^{+}$cells, albeit at a slow rate, for long-term persistence. Such hierarchical dynamics may be similar to the models regarding the mobilization of hematopoietic stem and progenitor cells, in which hematopoietic homeostasis is maintained predominantly by progenitors with limited self-renewing capability while stem cells are necessary for long-term hematopoiesis but only rarely give rise to these progenitors $(14,15)$. Analogously, $\mathrm{TCF}-1^{+}$cells act as reserve cells that can be called upon in very specific contexts such as checkpoint blockade, but likely do not contribute actively to CD8 $\mathrm{T}$ cell responses. Instead, $\mathrm{TIM}^{-} \mathrm{CX}^{-} \mathrm{CR} 1^{+}$cells, which are likely maintained by the IL-21-T-bet axis, serve as an intermediate progenitor population that constantly gives rise to $\mathrm{CX} 3 \mathrm{CR} 1^{+}$ $\mathrm{TIM}^{+}$cells as effectors. Thus, there is a hierarchy of CD8 T cells beginning with $\mathrm{TCF}-1^{+}$, and 
ending with $\mathrm{TIM}^{+} \mathrm{CX} 3 \mathrm{CR} 1^{+}$or $\mathrm{TIM}^{+} \mathrm{CX} 3 \mathrm{CR} 1^{-}$cells potentially through separate developmental pathways. This hierarchy could be essential for durable responses as it would prevent depletion of a long-term precursor pool during long-lasting infections, potentially resulting in clonal depletion.

An important takeaway of our work is the remarkable persistence of CD8 T cells that fall into the exhausted state during active infection. Specifically, while stem-like $\mathrm{TCF}-1^{+}$cells have been demonstrated to be long-lived, this phenotype is also the case for $\mathrm{CX} 3 \mathrm{CR} 1^{+}$cells. A substantial fraction of TCF $-1^{+}$memory CD8 $\mathrm{T}$ cells found after viral clearance are derived from $\mathrm{CX} 3 \mathrm{CR} 1^{+}$cells. Prior studies have utilized $T c f 7$-deficient mice to demonstrate a requirement for the stem-like population for persistence under competitive conditions, however, TIM3$\mathrm{CX} 3 \mathrm{CR} 1^{+}$cells do express a low amount of TCF1, providing an alternative explanation for overall cell loss. In addition, mice used for the transfer studies lack significant CD4 T cell responses, which likely secondarily results in loss of CX3CR1 cells $(8-10)$. New tools that allow for fate mapping directly from the TCF-1 ${ }^{+}$pool will help us to understand the extent of their dynamics and in different contexts.

T cell fates following infection have been defined as the formation of effector cells and memory precursor cells in acute infection from naive cells. However, recent data indicate that this process is not necessarily unidirectional with $\mathrm{KLRG}^{+}$short-lived effector cells able to dedifferentiate into memory cells with considerable proliferative capacity (39). In addition, deletion of the effector-promoting transcription factor Id 2 results in the default acquisition of memory phenotypes (40). Here we demonstrate a strikingly similar phenomenon even in exhausted CD8 T cells, with conversion of $\mathrm{CX} 3 \mathrm{CR} 1^{+} \mathrm{BLIMP}^{-1^{+}} \mathrm{TCF}-1^{\mathrm{lo} /-}$ cells to $\mathrm{CX} 3 \mathrm{CR} 1^{+} \mathrm{TCF}-1^{+}$cells after the infection is resolved. This result indicates cells other than TCF-1 ${ }^{\text {hi }}$ stem- or central memory- 
like cells retain the capacity to re-express TCF-1 under certain conditions, with undefined microenvironmental or intrinsic factors promoting this transition, possibly mediated by epigenetic reprogramming as reported in acute response (41). We expect to observe an equivalent type of memory $\mathrm{T}$ cell following cancer elimination, which may be important to prevent clinically detectable relapse. It remains to be determined how this memory cell type differs from $\mathrm{CX} 3 \mathrm{CR} 1^{-}$memory cells though the acquisition of imprinted identity during the effector phase. This knowledge will potentially enhance long-term immunity against chronic viral infection or cancers. 


\section{Materials and Methods}

\section{Mice and Infection}

Male C57BL/6N and B6-CD45.1 mice were purchased from Charles River Laboratory. Prdm1-EYFP, CD8 (E8I)-Cre, Tbx21 $1^{F}, \operatorname{Eomes}^{F}, B c l 6^{F}, I l 21 r, C x 3 c r 1^{C r e E R}$, Rosa26 $6^{L S L-t d T}-$ mice were originally obtained from The Jackson Laboratory. All mice were housed in a specific pathogen-free facility at Washington University in St. Louis, and were used for infection at 8 to 10 weeks of age unless stated otherwise. All experiments were performed according to a protocol approved by Washington University's Institutional Animal Care and Use Committee (IACUC). Stocks of LCMV were made by propagating virus by infection of BHK (baby hamster kidney) cells, followed by titering of culture supernatants by focus forming assay on Vero (African green monkey kidney) cells. For LCMV infection, mice were infected with 2 x $10^{5}$ plaque-forming units (PFU) of LCMV-Arm strain via the intraperitoneal route or 2 x $10^{6}$ (PFU) of LCMV-c13 by intravenous injection. For the quantification of plasma viral load, RNA was extracted from 10 $\mu l$ of plasma using Trizol (Life Technologies). Before RNA extraction a spike-in of exogenous control ERCC RNA was carried out and used to normalized viral loads following qPCR as described previously $(31,42)$.

\section{Bulk RNA-Seq}

To examine expression of different CD8 T cell subsets we utilized Prdm1-EYFP mice to separate $\mathrm{TCF}-1^{+}\left(\mathrm{YFP}^{-}\right)$and $\mathrm{TCF}-1^{-}\left(\mathrm{YFP}^{+}\right)$cells in the LCMV-specific CD8 $\mathrm{T}$ cells as previously described $(9,43)$. $\mathrm{CD}^{+} \mathrm{T}$ cells were first enriched from splenocytes using the Dynabeads FlowComp Mouse CD8 T cell kit followed by surface staining. We then sorted Prdm 1-EYFP ${ }^{-} \mathrm{TIM}^{-} \mathrm{CX}^{-} \mathrm{CR} 1^{-}$cells, which corresponded to $\mathrm{TCF}-1^{+}$stem-like CD8 $\mathrm{T}$ cells, and 
divided Prdm1-EYFP ${ }^{+}$cells into $\mathrm{CX}_{3 \mathrm{CR}} 1^{+} \mathrm{TIM}^{-}, \mathrm{CX}^{-} \mathrm{CR} 1^{+} \mathrm{TIM}^{+}$, and $\mathrm{CX} 3 \mathrm{CR} 1^{-} \mathrm{TIM}^{+}$ populations from splenocytes 16 days after infection with LCMV-c13.

Total RNA was extracted from $\sim 20-50 \mathrm{~K}$ sorted cells using the RNA XS Kit (Macherey Nagel) according to the manufacturer's instructions. cDNA synthesis and amplification were performed with Next Ultra RNA Library Preparation Kit (NEB). Libraries were sequenced on a HiSeq3000 (Illumina) in single-read mode, with a read length of 50 nucleotides producing 25 million reads per sample. Sequencing reads were mapped to NCBI mm9 using STAR with default parameters, and mapping rates were higher than 90\%. Transcripts with 4 TPM at least in one sample were initially filtered, followed by principal component analysis, unsupervised clustering, and profiling of subpopulation-specific gene expression using Phantasus and limma packages (V.15.1, https://artyomovlab.wustl.edu/phantasus/). The raw data will be deposited at NCBI GEO upon acceptance of the manuscript.

\section{Single-cell RNA-seq}

Single-cell RNA-seq libraries were prepared using the 10X Single Cell Immune Profiling Solution Kit (v1 Chemistry), according to the manufacturer's instructions. Briefly, FACS sorted cells were washed once with PBS $+0.04 \%$ BSA. Following reverse transcription and cell barcoding in droplets, emulsions were broken and cDNA purified using Dynabeads MyOne SILANE followed by PCR amplification (98C for $45 \mathrm{sec}$; 14 cycles of $98 \mathrm{C}$ for $20 \mathrm{sec}, 67 \mathrm{C}$ for $30 \mathrm{sec}, 72 \mathrm{C}$ for $1 \mathrm{~min} ; 72 \mathrm{C}$ for $1 \mathrm{~min})$. For gene expression library construction, $50 \mathrm{ng}$ of amplified cDNA was fragmented and end-repaired, double-sided size selected with SPRIselect beads, PCR amplified with sample indexing primers (98C for $45 \mathrm{sec}$; 14 cycles of 98C for 20 sec, $54 \mathrm{C}$ for $30 \mathrm{sec}, 72 \mathrm{C}$ for $20 \mathrm{sec}$; $72 \mathrm{C}$ for $1 \mathrm{~min}$ ), and double-sided size selected with 
SPRIselect beads. The prepared single-cell RNA libraries were sequenced on an Illumina HiSeq 4000 to a minimum sequencing depth of 25,000 reads/cell using the read lengths $28 \mathrm{bp}$ Read 1 , $8 \mathrm{bp}$ i7 Index, $91 \mathrm{bp}$ Read2. Single-cell RNA-seq reads were aligned to the mm10 reference genome and quantified using cellranger count (10X Genomics, version 3.1.0). Filtered genebarcodes matrices containing only barcodes with UMI counts passing threshold for cell detection were used for further analysis.

Additional analysis was performed using Seurat (version 3.1.2) (44). Cells with less than 200 genes detected or greater than 5\% mitochondrial RNA content were excluded from analysis. For clustering, raw UMI counts were log normalized and variable genes identified based on a variance stabilizing transformation. We assigned scores for S and G2/M cell cycle phase based on previously defined gene sets (45) using the CellCycleScoring function. Scaled z-scores for each gene were calculated using the ScaleData function and regressed against the S phase score and G2/M phase score to reduce clustering based on cell cycle. Scaled z-scores for variable genes were used as input into PCA. Clusters were identified using shared nearest neighbor (SNN) based clustering based on the first 10 PCs with $\mathrm{k}=15$ and resolution $=0.23$. The same principal components were used to generate the UMAP projections $(46,47)$, which were generated with a minimum distance of 0.1 and 30 neighbors. Expression of selected genes was plotted using log normalized gene expression values.

\section{Treatments}

For depletion of CD4 T cells, 200 micrograms of anti-CD4 (GK1.5, Leinco) was injected on -1 and +1 dpi. For administration of Tamoxifen (Sigma), $10 \mathrm{mg} / \mathrm{mL}$ solutions were prepared in Corn Oil (Sigma) and 1mg gavaged orally. 


\section{Cell Preparation, Cell Staining, and Flow Cytometry}

Single-cell suspensions of splenocytes were prepared by manual disruption with frosted glass slides. Lungs were minced with scissors and digested with Collagenase D (Sigma) and DNase I (Sigma) with agitation for 1 hour at 37C followed by enrichment of lymphocytes by a 40/70 Percoll gradient. Absolute live cell counts were determined by Trypan-blue exclusion using Vi-Cell (Beckman Coulter). Tetramer staining was performed using iTag-PE and APC LCMV gp33-44 and gp276-284 (MBL international). The following monoclonal antibodies were purchased from Biolegend unless otherwise indicated: FITC-conjugated anti-CD45.2 (104); PerCP-Cy5.5 conjugated anti-CD8ß (YTS156.7), anti-CD4 (GK1.5), anti-Ki-67 (16A8) PerCPeFlour710-conjugate anti-Eomes (eBioscience, Dan11mag), APC-conjugated CD366 (TIM-3, RMT3-23), anti-TNF- $\alpha$ (MP6-XT22), anti-granzyme B (QA16A02), anti-T-bet (4B1), antiCX3CR1 (SA011F11), Alexa 700-conjugated anti-CD44 (IM7), anti-CD45.2 (104), BV421conjugated anti-TIM3 (RMT3-23), BV605-conjugated CD4 (GK1.5), anti-CD45.1 (A20), antiCX3CR1(SA011F11), BV711-conjugated anti-CD4 (RM4-5), PE-conjugated anti-IFN- $\gamma$ (XMG1.2), anti-PE-Cy7-conjugated anti-PD-1 (29F.1A12) PE-Dazzle594-conjugated anti-B220 (RA3-6B2) and BUV395-conjugated anti-CD8 (53-6.7, BD) Anti-TCF-1 antibody (Cell Signaling, C63D9) and detected by Alexa 488-conjugated Donkey anti-rabbit polyclonal IgG (Thermo Fisher, Cat. \#R37118). Staining for transcription factors was performed using the Foxp3 staining kit (eBioscience) according to the manufacturer's instructions.

For intracellular cytokine staining, splenocytes were cultured in RPMI-1640 supplemented with $10 \%$ fetal bovine serum in the presence of $1 \mathrm{ug} / \mathrm{ml}$ of LCMV-gp peptide 
(Genscript) and $5 \mathrm{ug} / \mathrm{ml}$ of Brefeldin A (Biolegend) for 4 hours. Cells were stained for surface makers and then subject to LIVE/DEAD Aqua staining (Thermofisher) for 30 minutes at $4^{\circ} \mathrm{C}$ before being fixed with 4\% PFA for 10 minutes at R. Cells were then washed twice with $0.03 \%$ saponin in $2 \% \mathrm{FBS} / \mathrm{PBS}$ before being stained with the indicated antibodies in $0.3 \%$ Saponin in $2 \% \mathrm{FBS} / \mathrm{PBS}$ for $20 \mathrm{~min}$ at $4^{\circ} \mathrm{C}$.

BrdU incorporation assay was performed using the APC BrdU Flow Kit (BD Biosciences) according to the manufacturer's instruction with one-time intraperitoneal injection of $1 \mathrm{mg}$ of BrdU followed by tissue collection 12 hours later.

Stained samples were analyzed with FACS LSR Fortessa, X20 (BD), or Symphony A3 or sorted on Aria II or III. Data were processed with FlowJo Software (FlowJo. LLC).

Tumor Inoculation and Analysis

EG7 (ATCC) and MC38 (generous gift of Arlene Sharpe) cells were grown in RPMI and DMEM, respectively supplemented with 10\% FBS (Gibco), GlutaMAX (Gibco), and b-

Mercaptoethanol. Mice were shaved one day prior to subcutaneous inoculation of $10^{6}$ cells. For TIL analysis tumors were excised, minced, and digested with Collagenase B (Sigma), and DNase I for 30 minutes at $37^{\circ} \mathrm{C}$ to prepare single cell suspension.

\section{Statistical analysis}

$P$-values were calculated with an unpaired two-tailed Student's $t$-test or Mann-Whitney U-test for two-group comparisons and by one-way ANOVA for multi-group comparisons with the Tukey post hoc test using Prism 8 software. ${ }^{*} P<0.05$; ** $P<0.01$; *** $P<0.001$; *** $P<$ 0.0001 . 


\section{Supplementary Materials}

Fig. S1. Characterization of CX3CR1 expressing CD8 T cells in infection and tumors.

Fig. S2. Analysis of CX3CR1 Expression in TIL.

Fig. S3. Profiling of differentially expressed genes between distinct subpopulations of PD-1 ${ }^{+}$ CD8 T cells following LCMV-c13 infection.

Fig. S4. Time-course of CD4 $\mathrm{T}$ cell dependent $\mathrm{CD} 8^{+} \mathrm{T}$ cell response during LCMV-c13 infection.

Fig. S5. IL-21 signaling independent of germinal center response is necessary for the maintenance of CX3CR1 ${ }^{+}$PD- $1^{+} \mathrm{CD} 8 \mathrm{~T}$ cells in LCMV-c13-infected mice.

Fig. S6. Bcl6 is required for the formation of TCF- $1^{+}$stem-like CD8 T cells but not for CX3CR1 ${ }^{+}$cells in LCMV-c13 infection.

Fig. S7. Characterization of $\mathrm{Cx} 3 \mathrm{cr} 1^{\mathrm{creERT} 2 /+} \mathrm{ROSA} 26^{\mathrm{LSL}-\mathrm{tdT} /+}$ mice for in vivo labelling. 


\section{References:}

1. A. Gallimore, A. Glithero, A. Godkin, A. C. Tissot, A. Plückthun, T. Elliott, H. Hengartner, R. Zinkernagel, Induction and Exhaustion of Lymphocytic Choriomeningitis Virus-specific Cytotoxic T Lymphocytes Visualized Using Soluble Tetrameric Major Histocompatibility Complex Class I-Peptide Complexes. J. Exp. Med. 187, 1383-1393 (1998).

2. A. J. Zajac, J. N. Blattman, K. Murali-Krishna, D. J. Sourdive, M. Suresh, J. D. Altman, R. Ahmed, Viral immune evasion due to persistence of activated T cells without effector function. J. Exp. Med. 188, 2205-2213 (1998).

3. D. L. Barber, E. J. Wherry, D. Masopust, B. Zhu, J. P. Allison, A. H. Sharpe, G. J. Freeman, R. Ahmed, Restoring function in exhausted CD8 T cells during chronic viral infection. Nature. 439, 682-687 (2006).

4. H. Frebel, V. Nindl, R. A. Schuepbach, T. Braunschweiler, K. Richter, J. Vogel, C. A. Wagner, D. Loffing-Cueni, M. Kurrer, B. Ludewig, A. Oxenius, Programmed death 1 protects from fatal circulatory failure during systemic virus infection of mice. J. Exp. Med. 209, 2485-2499 (2012).

5. S. Raju, D. J. Verbaro, T. Egawa, PD-1 Signaling Promotes Control of Chronic Viral Infection by Restricting Type-I-Interferon-Mediated Tissue Damage. Cell Rep. 29, 25562564.e3 (2019).

6. E. K. Cartwright, L. Spicer, S. A. Smith, D. Lee, R. Fast, S. Paganini, B. O. Lawson, M. Nega, K. Easley, J. E. Schmitz, S. E. Bosinger, M. Paiardini, A. Chahroudi, T. H. Vanderford, J. D. Estes, J. D. Lifson, C. A. Derdeyn, G. Silvestri, CD8(+) Lymphocytes Are Required for Maintaining Viral Suppression in SIV-Infected Macaques Treated with Short-Term Antiretroviral Therapy. Immunity. 45, 656-668 (2016).

7. M. A. Paley, D. C. Kroy, P. M. Odorizzi, J. B. Johnnidis, D. V. Dolfi, B. E. Barnett, E. K. Bikoff, E. J. Robertson, G. M. Lauer, S. L. Reiner, E. J. Wherry, Progenitor and terminal subsets of CD8+ T cells cooperate to contain chronic viral infection. Science. 338, 12201225 (2012).

8. S. J. Im, M. Hashimoto, M. Y. Gerner, J. Lee, H. T. Kissick, M. C. Burger, Q. Shan, J. S. Hale, J. Lee, T. H. Nasti, A. H. Sharpe, G. J. Freeman, R. N. Germain, H. I. Nakaya, H.-H. Xue, R. Ahmed, Defining CD8+ T cells that provide the proliferative burst after PD-1 therapy. Nature. 537, 417-421 (2016).

9. T. Wu, Y. Ji, E. A. Moseman, H. C. Xu, M. Manglani, M. Kirby, S. M. Anderson, R. Handon, E. Kenyon, A. Elkahloun, W. Wu, P. A. Lang, L. Gattinoni, D. B. McGavern, P. L. Schwartzberg, The TCF1-Bcl6 axis counteracts type I interferon to repress exhaustion and maintain T cell stemness. Science immunology. 1, eaai8593-eaai8593 (2016).

10. D. T. Utzschneider, M. Charmoy, V. Chennupati, L. Pousse, D. P. Ferreira, S. CalderonCopete, M. Danilo, F. Alfei, M. Hofmann, D. Wieland, S. Pradervand, R. Thimme, D. 
Zehn, W. Held, T Cell Factor 1-Expressing Memory-like CD8+ T Cells Sustain the Immune Response to Chronic Viral Infections. Immunity. 45, 415-427 (2016).

11. H. Li, A. M. van der Leun, I. Yofe, Y. Lubling, D. Gelbard-Solodkin, A. C. J. van Akkooi, M. van den Braber, E. A. Rozeman, J. B. A. G. Haanen, C. U. Blank, H. M. Horlings, E. David, Y. Baran, A. Bercovich, A. Lifshitz, T. N. Schumacher, A. Tanay, I. Amit, Dysfunctional CD8 T Cells Form a Proliferative, Dynamically Regulated Compartment within Human Melanoma. Cell. 176, 775-789.e18 (2019).

12. B. C. Miller, D. R. Sen, R. Al Abosy, K. Bi, Y. V. Virkud, M. W. LaFleur, K. B. Yates, A. Lako, K. Felt, G. S. Naik, M. Manos, E. Gjini, J. R. Kuchroo, J. J. Ishizuka, J. L. Collier, G. K. Griffin, S. Maleri, D. E. Comstock, S. A. Weiss, F. D. Brown, A. Panda, M. D. Zimmer, R. T. Manguso, F. S. Hodi, S. J. Rodig, A. H. Sharpe, W. N. Haining, Subsets of exhausted $\mathrm{CD} 8+\mathrm{T}$ cells differentially mediate tumor control and respond to checkpoint blockade. Nat. Immunol. 20, 326-336 (2019).

13. Z. Chen, Z. Ji, S. F. Ngiow, S. Manne, Z. Cai, A. C. Huang, J. Johnson, R. P. Staupe, B. Bengsch, C. Xu, S. Yu, M. Kurachi, R. S. Herati, L. A. Vella, A. E. Baxter, J. E. Wu, O. Khan, J.-C. Beltra, J. R. Giles, E. Stelekati, L. M. McLane, C. W. Lau, X. Yang, S. L. Berger, G. Vahedi, H. Ji, E. J. Wherry, TCF-1-Centered Transcriptional Network Drives an Effector versus Exhausted CD8 T Cell-Fate Decision. Immunity. 51, 840-855.e5 (2019).

14. J. Sun, A. Ramos, B. Chapman, J. B. Johnnidis, L. Le, Y.-J. Ho, A. Klein, O. Hofmann, F. D. Camargo, Clonal dynamics of native haematopoiesis. Nature. 514, 322-327 (2014).

15. K. Busch, K. Klapproth, M. Barile, M. Flossdorf, T. Holland-Letz, S. M. Schlenner, M. Reth, T. Höfer, H.-R. Rodewald, Fundamental properties of unperturbed haematopoiesis from stem cells in vivo. Nature. 518, 542-546 (2015).

16. J. M. Bernitz, H. S. Kim, B. MacArthur, H. Sieburg, K. Moore, Hematopoietic Stem Cells Count and Remember Self-Renewal Divisions. Cell. 167, 1296-1309.e10 (2016).

17. M. Ahmadzadeh, L. A. Johnson, B. Heemskerk, J. R. Wunderlich, M. E. Dudley, D. E. White, S. A. Rosenberg, Tumor antigen-specific CD8 T cells infiltrating the tumor express high levels of PD-1 and are functionally impaired. Blood. 114, 1537-1544 (2009).

18. S. D. Blackburn, A. Crawford, H. Shin, A. Polley, G. J. Freeman, E. J. Wherry, Tissuespecific differences in PD-1 and PD-L1 expression during chronic viral infection: implications for CD8 T-cell exhaustion. J. Virol. 84, 2078-2089 (2010).

19. Y. W. Jung, R. L. Rutishauser, N. S. Joshi, A. M. Haberman, S. M. Kaech, Differential localization of effector and memory CD8 T cell subsets in lymphoid organs during acute viral infection. J. Immunol. 185, 5315-5325 (2010).

20. C. X. Dominguez, R. A. Amezquita, T. Guan, H. D. Marshall, N. S. Joshi, S. H. Kleinstein, S. M. Kaech, The transcription factors ZEB2 and T-bet cooperate to program cytotoxic T cell terminal differentiation in response to LCMV viral infection. J. Exp. Med. 212, 20412056 (2015). 
21. T. Guan, C. X. Dominguez, R. A. Amezquita, B. J. Laidlaw, J. Cheng, J. Henao-Mejia, A. Williams, R. A. Flavell, J. Lu, S. M. Kaech, ZEB1, ZEB2, and the miR-200 family form a counterregulatory network to regulate CD8+T cell fates. J. Exp. Med. 215, 1153-1168 (2018).

22. K. D. Omilusik, J. A. Best, B. Yu, S. Goossens, A. Weidemann, J. V. Nguyen, E. Seuntjens, A. Stryjewska, C. Zweier, R. Roychoudhuri, Others, Transcriptional repressor ZEB2 promotes terminal differentiation of CD8+ effector and memory $\mathrm{T}$ cell populations during infection. J. Exp. Med. 212, 2027-2039 (2015).

23. A. M. Intlekofer, A. Banerjee, N. Takemoto, S. M. Gordon, C. S. Dejong, H. Shin, C. A. Hunter, E. J. Wherry, T. Lindsten, S. L. Reiner, Anomalous type 17 response to viral infection by CD8+ T cells lacking T-bet and eomesodermin. Science. 321, 408-411 (2008).

24. C. Kao, K. J. Oestreich, M. A. Paley, A. Crawford, J. M. Angelosanto, M.-A. A. Ali, A. M. Intlekofer, J. M. Boss, S. L. Reiner, A. S. Weinmann, E. J. Wherry, Transcription factor Tbet represses expression of the inhibitory receptor PD-1 and sustains virus-specific CD8+ T cell responses during chronic infection. Nat. Immunol. 12, 663-671 (2011).

25. H. Elsaesser, K. Sauer, D. G. Brooks, IL-21 is required to control chronic viral infection. Science. 324, 1569-1572 (2009).

26. A. Fröhlich, J. Kisielow, I. Schmitz, S. Freigang, A. T. Shamshiev, J. Weber, B. J. Marsland, A. Oxenius, M. Kopf, IL-21R on T cells is critical for sustained functionality and control of chronic viral infection. Science. 324, 1576-1580 (2009).

27. J. S. Yi, M. Du, A. J. Zajac, A vital role for interleukin-21 in the control of a chronic viral infection. Science. 324, 1572-1576 (2009).

28. A. P. R. Sutherland, N. Joller, M. Michaud, S. M. Liu, V. K. Kuchroo, M. J. Grusby, IL-21 promotes CD8+ CTL activity via the transcription factor T-bet. J. Immunol. 190, 39773984 (2013).

29. E. J. Wherry, J. N. Blattman, K. Murali-Krishna, R. van der Most, R. Ahmed, Viral Persistence Alters CD8 T-Cell Immunodominance and Tissue Distribution and Results in Distinct Stages of Functional Impairment. J. Virol. 77, 4911-4927 (2003).

30. J. A. Harker, G. M. Lewis, L. Mack, E. I. Zuniga, Late interleukin-6 escalates T follicular helper cell responses and controls a chronic viral infection. Science. 334, 825-829 (2011).

31. C. Chou, D. J. Verbaro, E. Tonc, M. Holmgren, M. Cella, M. Colonna, D. Bhattacharya, T. Egawa, The Transcription Factor AP4 Mediates Resolution of Chronic Viral Infection through Amplification of Germinal Center B Cell Responses. Immunity. 45, 570-582 (2016).

32. D. T. Utzschneider, A. Legat, S. A. Fuertes Marraco, L. Carrié, I. Luescher, D. E. Speiser, D. Zehn, T cells maintain an exhausted phenotype after antigen withdrawal and population reexpansion. Nat. Immunol. 14, 603-610 (2013). 
33. L. M. McLane, M. S. Abdel-Hakeem, E. J. Wherry, CD8 T Cell Exhaustion During Chronic Viral Infection and Cancer. Annu. Rev. Immunol. (2019), doi:10.1146/annurev-immunol041015-055318.

34. Y. Yan, S. Cao, X. Liu, S. M. Harrington, W. E. Bindeman, A. A. Adjei, J. S. Jang, J. Jen, Y. Li, P. Chanana, A. S. Mansfield, S. S. Park, S. N. Markovic, R. S. Dronca, H. Dong, CX3CR1 identifies PD-1 therapy-responsive CD8+ T cells that withstand chemotherapy during cancer chemoimmunotherapy. JCI Insight. 3 (2018), doi:10.1172/jci.insight.97828.

35. J. P. Böttcher, M. Beyer, F. Meissner, Z. Abdullah, J. Sander, B. Höchst, S. Eickhoff, J. C. Rieckmann, C. Russo, T. Bauer, T. Flecken, D. Giesen, D. Engel, S. Jung, D. H. Busch, U. Protzer, R. Thimme, M. Mann, C. Kurts, J. L. Schultze, W. Kastenmüller, P. A. Knolle, Functional classification of memory CD8(+) T cells by CX3CR1 expression. Nat. Commun. 6, 8306 (2015).

36. C. Gerlach, E. A. Moseman, S. M. Loughhead, D. Alvarez, A. J. Zwijnenburg, L. Waanders, R. Garg, J. C. de la Torre, U. H. von Andrian, The Chemokine Receptor CX3CR1 Defines Three Antigen-Experienced CD8 T Cell Subsets with Distinct Roles in Immune Surveillance and Homeostasis. Immunity. 45, 1270-1284 (2016).

37. W. H. Hudson, J. Gensheimer, M. Hashimoto, A. Wieland, R. M. Valanparambil, P. Li, J.X. Lin, B. T. Konieczny, S. J. Im, G. J. Freeman, W. J. Leonard, H. T. Kissick, R. Ahmed, Proliferating Transitory T Cells with an Effector-like Transcriptional Signature Emerge from PD-1+ Stem-like CD8+ T Cells during Chronic Infection. Immunity. 0 (2019), doi:10.1016/j.immuni.2019.11.002.

38. R. Zander, D. Schauder, G. Xin, C. Nguyen, X. Wu, A. Zajac, W. Cui, CD4+ T Cell Help Is Required for the Formation of a Cytolytic CD8+ T Cell Subset that Protects against Chronic Infection and Cancer. Immunity. 0 (2019), doi:10.1016/j.immuni.2019.10.009.

39. D. Herndler-Brandstetter, H. Ishigame, R. Shinnakasu, V. Plajer, C. Stecher, J. Zhao, M. Lietzenmayer, L. Kroehling, A. Takumi, K. Kometani, T. Inoue, Y. Kluger, S. M. Kaech, T. Kurosaki, T. Okada, R. A. Flavell, KLRG1+ Effector CD8+ T Cells Lose KLRG1, Differentiate into All Memory T Cell Lineages, and Convey Enhanced Protective Immunity. Immunity. 48, 716-729.e8 (2018).

40. K. D. Omilusik, M. S. Nadjsombati, L. A. Shaw, B. Yu, J. J. Milner, A. W. Goldrath, Sustained $\mathrm{Id} 2$ regulation of E proteins is required for terminal differentiation of effector CD8+ T cells. J. Exp. Med. 215, 773-783 (2018).

41. B. Youngblood, J. S. Hale, H. T. Kissick, E. Ahn, X. Xu, A. Wieland, K. Araki, E. E. West, H. E. Ghoneim, Y. Fan, P. Dogra, C. W. Davis, B. T. Konieczny, R. Antia, X. Cheng, R. Ahmed, Effector CD8 T cells dedifferentiate into long-lived memory cells. Nature. 552, 404-409 (2017).

42. M. M. McCausland, S. Crotty, Quantitative PCR technique for detecting lymphocytic choriomeningitis virus in vivo. J. Virol. Methods. 147, 167-176 (2008). 
43. D. R. Fooksman, M. C. Nussenzweig, M. L. Dustin, Myeloid cells limit production of antibody-secreting cells after immunization in the lymph node. J. Immunol. 192, 1004-1012 (2014).

44. T. Stuart, A. Butler, P. Hoffman, C. Hafemeister, E. Papalexi, W. M. Mauck 3rd, Y. Hao, M. Stoeckius, P. Smibert, R. Satija, Comprehensive Integration of Single-Cell Data. Cell. 177, 1888-1902.e21 (2019).

45. I. Tirosh, B. Izar, S. M. Prakadan, M. H. Wadsworth 2nd, D. Treacy, J. J. Trombetta, A. Rotem, C. Rodman, C. Lian, G. Murphy, M. Fallahi-Sichani, K. Dutton-Regester, J.-R. Lin, O. Cohen, P. Shah, D. Lu, A. S. Genshaft, T. K. Hughes, C. G. K. Ziegler, S. W. Kazer, A. Gaillard, K. E. Kolb, A.-C. Villani, C. M. Johannessen, A. Y. Andreev, E. M. Van Allen, M. Bertagnolli, P. K. Sorger, R. J. Sullivan, K. T. Flaherty, D. T. Frederick, J. JanéValbuena, C. H. Yoon, O. Rozenblatt-Rosen, A. K. Shalek, A. Regev, L. A. Garraway, Dissecting the multicellular ecosystem of metastatic melanoma by single-cell RNA-seq. Science. 352, 189-196 (2016).

46. E. Becht, L. McInnes, J. Healy, C.-A. Dutertre, I. W. H. Kwok, L. G. Ng, F. Ginhoux, E. W. Newell, Dimensionality reduction for visualizing single-cell data using UMAP. Nat. Biotechnol. (2018), doi:10.1038/nbt.4314.

47. L. McInnes, J. Healy, J. Melville, UMAP: Uniform Manifold Approximation and Projection for Dimension Reduction. arXiv [stat.ML] (2018), (available at http://arxiv.org/abs/1802.03426). 


\section{Acknowledgements}

We thank M. Colonna and M. Cella for LCMV stocks, G. Randolph for Cx3crl-creERT2 mice, Arlene Sharpe for MC38 cells, C. Fuji for the maintenance of the mouse colony, and C-S. Hsieh for discussion and critical reading of the manuscript. This study was supported by NIH grants R01AI130152-01A1 and R03AI139875-01 (to T.E.), T32HL007317 (to S.R.), and T32GM007200 (to S.R. and D.J.V.). T.E. is a Scholar of the Leukemia and Lymphoma Society (www.1ls.org).

\section{Author Contributions}

SR and TE designed the study. SR, YX, BD, KEY, ET, EB, DJV and TE conducted experiments. SR, YX, ATS and TE interpreted results. SR and TE wrote the manuscript with comments from all authors.

\section{Declaration of Interests}

The authors have no competing interests related to the present work.

\section{Data Availability}

Bulk RNA-seq data are deposited to NCBI Gene Expression Omnibus under the accession number GSE145910. Data will be made publicly accessible upon acceptance of the manuscript. 


\section{Figure Legends}

\section{Fig. 1. CX3CR1 marks a proliferative subset of exhausted $T$ cells.}

A. UMAP analysis of scRNA-seq data of 2,141 gp-33 specific CD8 T cells on 21 dpi with LCMV-c13. Right panels show the expression of indicated genes.

B, C. Flow cytometry showing expression of TIM3, CX3CR1, CD44 and TCF-1 in LCMV gp33-specific CD8 T cells 4 weeks after infection of C57BL/6 mice with LCMV-c13. Numbers indicate percentages of gated cells in each parental population shown in the figure. Data are representative of 8 mice.

D. BrdU incorporation as measured by flow cytometry by LCMV gp33-specific CD8 T cells in the indicated subpopulations 12 hours after intraperitoneal administration of $1 \mathrm{mg}$ BrdU on 22 dpi with LCMV-c13. Data are representative of three independent experiments with $n=3$ mice each.

E. Expression of PD-1 measured by flow cytometry in the indicated population of LCMV-gp33specific CD8 T cells on 22 dpi, quantified in the right panel. Data are representative of 3 independent experiments with $\mathrm{n}=3$ mice each.

Fig. 2. Gene expression analysis of exhausted CD8 $\mathrm{T}$ cell subsets defined by CX3CR1.

A. A Principal Component Analysis (PCA) plot derived from bulk RNA-seq analysis of the indicated subpopulations of PD- ${ }^{+}$CD8 T cells on 16 dpi.

B. Heat maps showing expression of indicated genes by distinct subsets of PD- $1^{+} \mathrm{CD} 8 \mathrm{~T}$ cells. Expression values were averaged from three independent samples for each population and colorcoded based on row mean and fold-changes. 
C. Gene Set Enrichment Analysis (GSEA) showing pathways associated with genes that were differentially expressed between $\mathrm{TCF}-1^{+}$and $\mathrm{TCF}-1^{-} \mathrm{TIM}^{+} \mathrm{CX} 3 \mathrm{CR} 1^{+}$populations.

D. Expression of Granzyme B (GZMB) protein by gp33-specific CD8 T cells shown by frequencies of cells expressing GZMB and by mean fluorescence intensity (MFI) on 28 dpi. Data are representative of 2 independent experiments with $n>5$ mice in total.

E. Flow Cytometry plots showing expression of T-bet and Eomes in the indicated subsets of gp33-specific CD8 T cells in the spleen on 22 dpi with LCMV-c13 infection. Data are representative of 3 independent experiments with $n=5$ mice each.

Dots in the graphs in (A), (D) and (E) indicate individual mouse and data in (D) and (E) are shown by mean \pm SD. Statistical differences in (D) and (E) were tested using one-way ANOVA with a Tukey post-hoc test.

Fig.3. IL-21 and CD4 $\mathrm{T}$ cells are required for the maintenance of CX3CR1 subset of PD-1+ CD8 T cells.

A, B. Flow Cytometry showing expression of CX3CR1 and TIM3 (A) in TCF-1 ${ }^{-}$gp33-specific CD8 T cells in control and CD4 T cell-depleted mice on the indicated dpi with LCMV-c13. (A) shows representative plots from 4-5 mice and data from replicates are shown in (B).

C. Expression of T-bet and Eomes in in gp33-specific CD8 T cells in control and CD4 T celldepleted mice on 30 dpi. Frequencies of T-bet ${ }^{\text {hi }}$ Eomes $^{\text {lo }}$ cells are indicated with polygon gates. Data are representative from 3 independent experiments with $n=3$ mice in each.

D, E. Flow Cytometry showing expression of TCF-1, CX3CR1, and TIM3 in gp33-specific cells in spleen of $I l 21 r^{+/+}$and $I l 21 r^{-/-}$mice on 35 dpi with LCMV-c13 (D). Data are representative of 
two independent experiments with $\mathrm{n}>3$ mice in each experiment per genotype. Data in (B), (C), and $(\mathrm{E})$ are shown with mean $\pm \mathrm{SD}$.

Fig.4. T-bet and Eomes are non-redundantly required for differentiation of PD-1 ${ }^{+}$CD8 T cells in response to chronic viral infection.

A, B. Flow Cytometry showing expression of TCF-1, CX3CR1, and TIM3 by gp33-specific

CD8 T cells in control $T b x 21^{\mathrm{F} / \mathrm{F}}$ and CD8-cre $T b x 21^{\mathrm{F} / \mathrm{F}}$ mice on 29 dpi with LCMV-c13.

Representative flow cytometry plots are shown in (A) with frequencies of gated cells in each parental population, and statistical analyses are shown in (B). Data are representative of 3 independent experiments with $\mathrm{n}>4$ mice per genotype in each experiment.

C. LCMV-gp mRNA abundance in plasma as assessed by qRT-PCR in $T b \times 21^{\mathrm{F} / \mathrm{F}}$ and CD8-cre $\operatorname{Tb} \times 21^{\mathrm{F} / \mathrm{F}}$ mice on 100 dpi with LCMV-c13. Horizontal bars indicate median for samples in each genotype and the statistical differences were assessed by Mann-Whitney U-test.

D, E. Flow Cytometry showing expression of TCF-1, CX3CR1, and TIM3 in control Eomes ${ }^{\mathrm{F} / \mathrm{F}}$ and CD8-cre Eomes $^{\mathrm{F} / \mathrm{F}}$ mice on 28 dpi with LCMV-c13. Data are representative of 3 independent experiments with $\mathrm{n}>4$ mice per genotype in each experiment.

F. Viral Load as assessed by qRT-PCR in plasma from Eomes $^{\mathrm{F} / \mathrm{F}}$ and CD8-cre Eomes $^{\mathrm{F} / \mathrm{F}}$ mice on 100 dpi with after LCMV-c13. Data in (B) and (E) are shown with mean \pm SD with statistical tests using unpaired $t$-test.

Fig.5. Lineage tracing reveals substantial stability and persistence of CX3CR1 ${ }^{+}$PD- ${ }^{+}$CD8 T cells. 
A. Experimental schematic of tamoxifen administration to $C x 3 c r 1^{\text {creERT2/+ }} \operatorname{ROSA26^{\mathrm {LSL}-\mathrm {tdT}/+}}$ (R26tdT) mice infected with LCMV-c13 and analysis (B-E).

B. Frequency of td-Tomato $(\mathrm{tdT})^{+}$cells within $\mathrm{CX} 3 \mathrm{CR} 1^{+} \mathrm{PD}-1^{+} \mathrm{CD} 8 \mathrm{~T}$ cells in the PBMC in $\mathrm{Cx} 3 \mathrm{crl} \mathrm{I}^{\mathrm{CreER} /+} \mathrm{R} 26 \mathrm{tdT}$ mice at indicated time points after infection and tamoxifen administration in (A). Data are representative of 2 independent experiments with at least 3 mice each.

C. Flow cytometry plots showing expression of CX3CR1 and TIM3 in total and $\mathrm{tdT}^{+} \mathrm{TCF}-1^{-}$ gp33-specific CD8 T cells in the spleen of $C x 3 c r 1^{\text {creERT2/+ }} R 26$ tdT mice treated as shown in (A). Pooled data from two independent experiments are shown with mean $\pm \mathrm{SD}$.

D. Frequencies of $\operatorname{tdT}^{+}$cells within indicated subpopulations from samples in (C), quantified in the panel.

E. Flow cytometry plots showing expression of CX3CR1 and TIM3 in total and $\mathrm{tdT}^{+} \mathrm{TCF}-1^{-}$ gp33-specific CD8 T cells in the spleen of $C x 3 c r 1^{\text {creERT2/+ }} R 26 \operatorname{tdT}$ mice, which were given Tamoxifen on 22 dpi and analyzed on 30 dpi, quantified in the right panel. Data are representative of 2 independent experiments with $n=4$ mice each.

Fig.6. $\mathrm{CX} 3 \mathrm{CR} 1^{+} \mathrm{CD8} \mathrm{T}$ cells during the chronic phase give rise to $\mathrm{TCF}-1^{+}$memory cells following viral clearance.

A, B. Flow cytometry plots showing expression of tdTomato (tdT), TCF-1, CX3CR1 and TIM3 in gp-33-specific CD8 T cells in the splenocytes in LCMV-c13-infected $\mathrm{Cx} 3 \mathrm{cr} \mathrm{I}^{\mathrm{creERT} 2 /+} \mathrm{R} 26 \mathrm{tdT}$ mice treated with Tamoxifen on 28 dpi and analyzed on $>120$ dpi. Representative flow plots from two independent experiments are shown in (A) and data from replicates are shown with mean $\pm \mathrm{SD}$ in $(\mathrm{B})$. 
C. Expression of IFN- $\gamma$ and TNF- $\alpha$ in indicated subsets of CD8 T cells in the spleen of d29 dpi LCMV-c13-infected mice, >120 dpi LCMV-Armstrong-infected mice, or >120 dpi LCMV-c13infected mice following stimulation with LCMV-gp33 peptide ex vivo for four hours.

D. Schematic of adoptive transfer experiment to assess the capability of secondary expansion of $\mathrm{CX}_{3} \mathrm{CR} 1^{+}$and $\mathrm{CX} 3 \mathrm{CR} 1^{-} \mathrm{CD} 8 \mathrm{~T}$ cells that were sorted from LCMV Arm and LCMV-c13 infected mice. The right panel shows data from replicates. Data are representative from 2 independent experiments with $\mathrm{n}=2$ donor mice and $\mathrm{n}=5$ recipient mice per experiment. 


\section{Supplementary Figure Legends}

\section{Supplementary Fig. 1. Characterization of CX3CR1 expressing CD8 T cells in infection} and tumors.

A. UMAP analysis of scRNA-seq data of gp-33-specific CD8 T cells on 21 dpi with LCMV-c13 showing expression of indicated genes.

B, C. Expression of PD-1 and Ki-67 in subpopulations of gp33-specific CD8 T cells defined by TIM3 and CX3CR1 in LCMV-c13-infected C57BL/6 mice at different time points after infection. Data are representative of two experiments with $n=5$ mice.

D. Flow cytometry analyzing expression of TIM3, CX3CR1, and TCF-1 by LCMV gp33specific CD8 T cells in lungs of mice that were intravenously injected with 3 ug of CD45.2 three minutes before euthanasia. Data are representative of 2 independent experiments with $n=3$ mice each.

Each dot in the graphs indicates an individual mouse that was examined, and data are shown by mean \pm SD. Statistical differences were tested using one-way ANOVA with a Tukey post-hoc test (C) and student's t-test (D).

\section{Supplementary Fig. 2. Analysis of CX3CR1 Expression in TIL.}

A, B. Expression of TCF-1, TIM3 and CX3CR1 in PD- $1^{+}$CD8 T cells infiltrating in the MC38 tumors (A) 19 days and E.G7 tumors (B) 8 days after subcutaneous inoculation. Data are representative of 3 independent experiments with $n>3$ mice each.

\section{Supplementary Fig. 3. Profiling of differentially expressed genes between distinct subpopulations of PD-1 ${ }^{+}$CD8 T cells following LCMV-c13 infection.}


A. Heatmap showing K-mean clustering of genes differentially expressed between distinct subpopulations on 16 dpi. Gene expression levels are shown as z-score normalized to each row mean.

B. Table showing top 15 differentially expressed genes for each pairwise between two indicated populations, as determined by significance based on t-statistics. Genes shown are more highly expressed in the population listed horizontally on the top row compared to one listed vertically on the left side.

\section{Supplementary Fig. 4. Time-course of $\mathrm{CD4} \mathrm{T}$ cell dependent $\mathrm{CD8}^{+} \mathrm{T}$ cell response during LCMV-c13 infection.}

A, B. Flow Cytometry showing expression of CD44 and H-2Db(gp33-41)-specific TCR of total CD8 T cells as well as expression of TCF-1 and TIM3 in gp33-specific CD8 T cells in the spleen of control and CD4 T cell-depleted mice on the indicated time points after infection. (A) shows representative plots from 3-5 mice and data from replicates are shown in (B) with mean \pm SD.

\section{Supplementary Fig. 5. IL-21 signaling independent of germinal center response is necessary for the maintenance of $\mathrm{CX} 3 \mathrm{CR} 1^{+} \mathrm{PD}^{+} \mathrm{1}^{+} \mathrm{CD8} \mathrm{T}$ cells in $\mathrm{LCMV}$-c13-infected mice.} A, B. Flow cytometry showing expression of LCMV-gp33-specific TCR and CD44 in CD8 T cells in $I l 21 r^{+/+}$and $I l 21 r^{-/-}$mice on 35 dpi. Data are representative of two independent experiments with $\mathrm{n}>3$ mice in each experiment per genotype.

C, D. Flow cytometry showing expression of TIM3 and CX3CR1 in TCF-1- gp33-specific CD8 T cells in muMT mice. Representative plots shown in (C) with data from replicates in (D) with mean $\pm \mathrm{SD}$. 


\section{Supplementary Fig. 6. Bcl6 is required for the formation of TCF-1 ${ }^{+}$stem-like CD8 $\mathrm{T}$ cells but not for CX3CR1 ${ }^{+}$cells in $\mathrm{LCMV}$-c13 infection.}

Flow cytometry data showing TCF-1 and CX3CR1 in gp33-specific CD8 T cells on 8 dpi (A).

Data from replicates are shown in (B) with mean \pm SD.

\section{Supplementary Fig. 7. Characterization of $\mathrm{Cx} 3 \mathrm{cr} 1^{\mathrm{creERT2/+}} \mathrm{ROSA26^{ \textrm {LSL } - \mathrm { tdT } / + }}$ mice for in vivo labelling.}

A. Flow cytometry plots showing expression of tdT and CX3CR1 in the PBMC of mice on 10 dpi in the indicated genotypes of mice following oral administration of Tamoxifen on 8 and 9 dpi.

B. Flow cytometry plots showing expression of tdT and TCF-1 in gp33-specific CD8 T cells 16 hours following tamoxifen administration on $8 \mathrm{dpi}$. Data from replicates are shown in the right panel. Data are representative of 2 independent experiments with at least 3 mice each.

C. Flow cytometry plots showing expression of tdT and CX3CR1 in gp33-specific CD8 T cells 24 hours following tamoxifen administration on 22 dpi. Data are representative of 2 independent experiments with at least 3 mice each. 


\section{Figure 2}

A

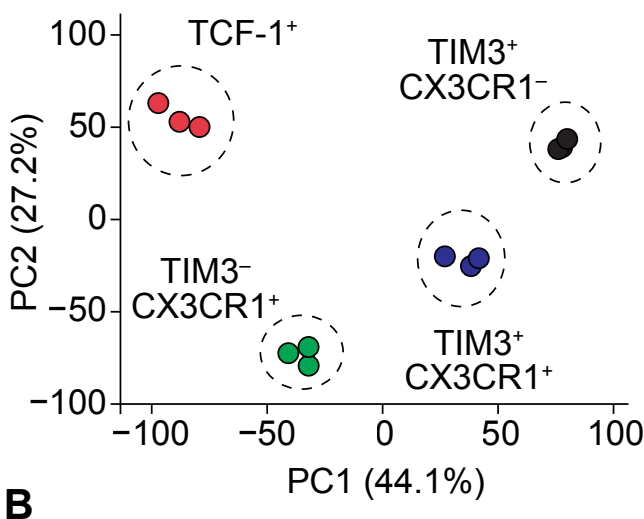

B

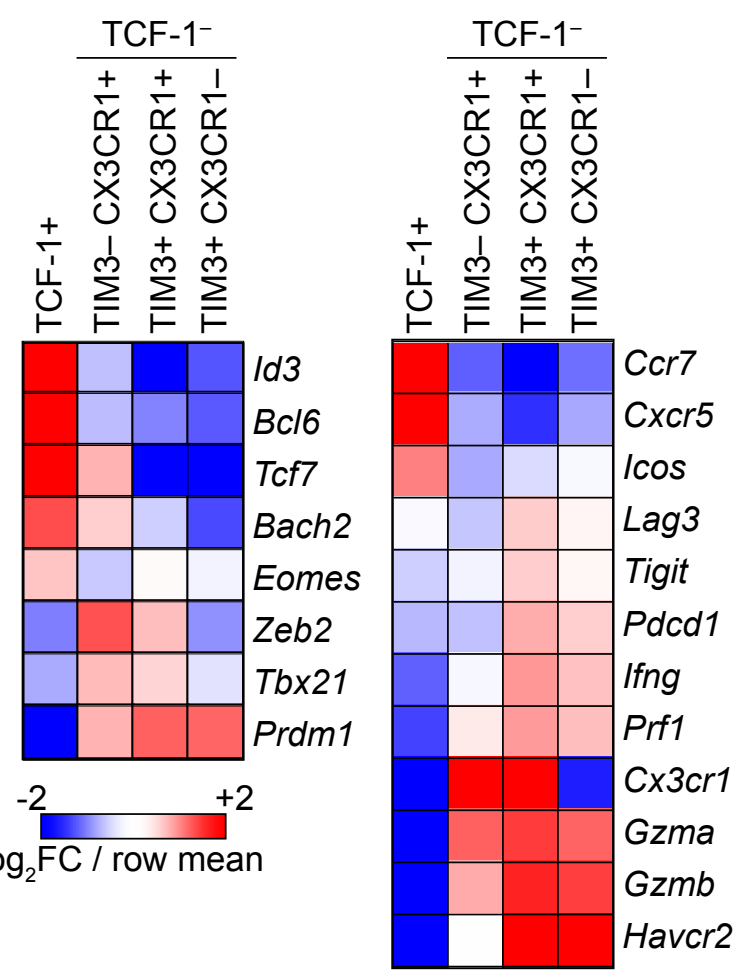

C
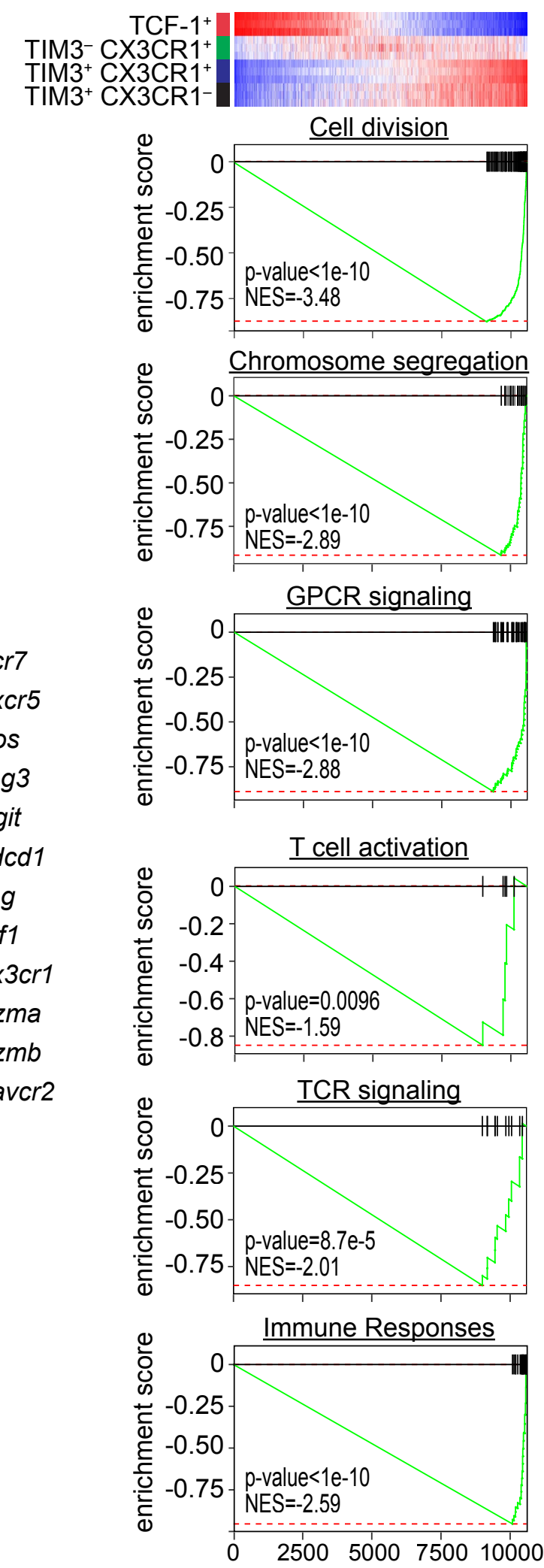

D
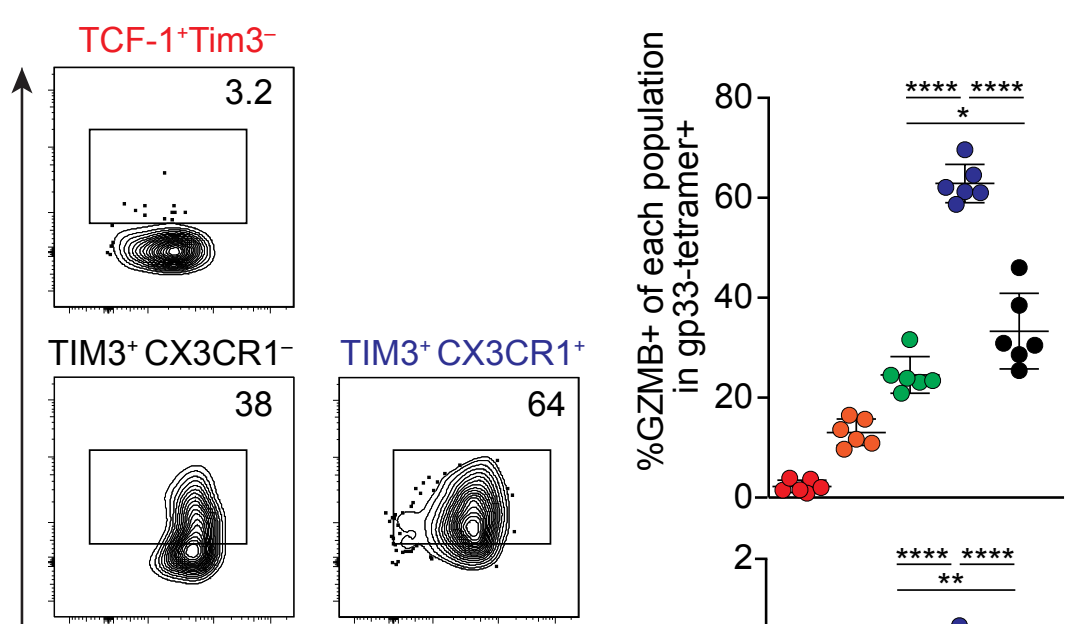

$\sum_{N}^{\infty}$
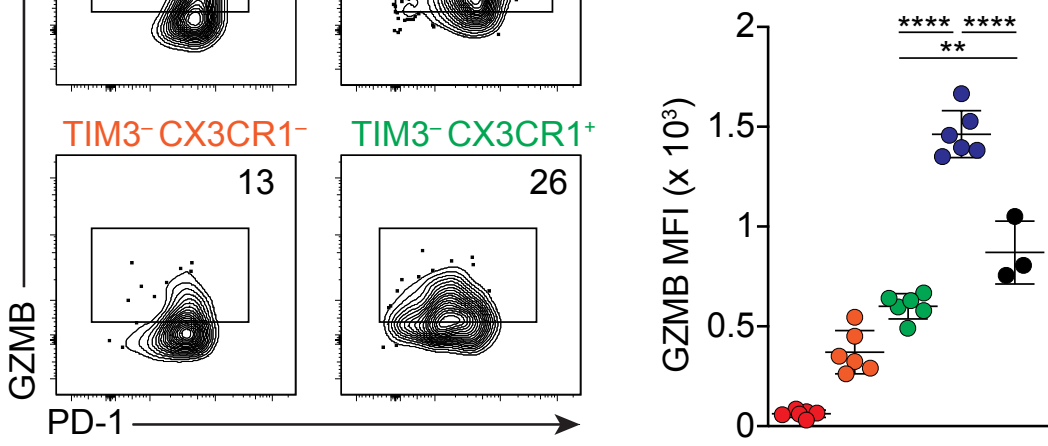

E
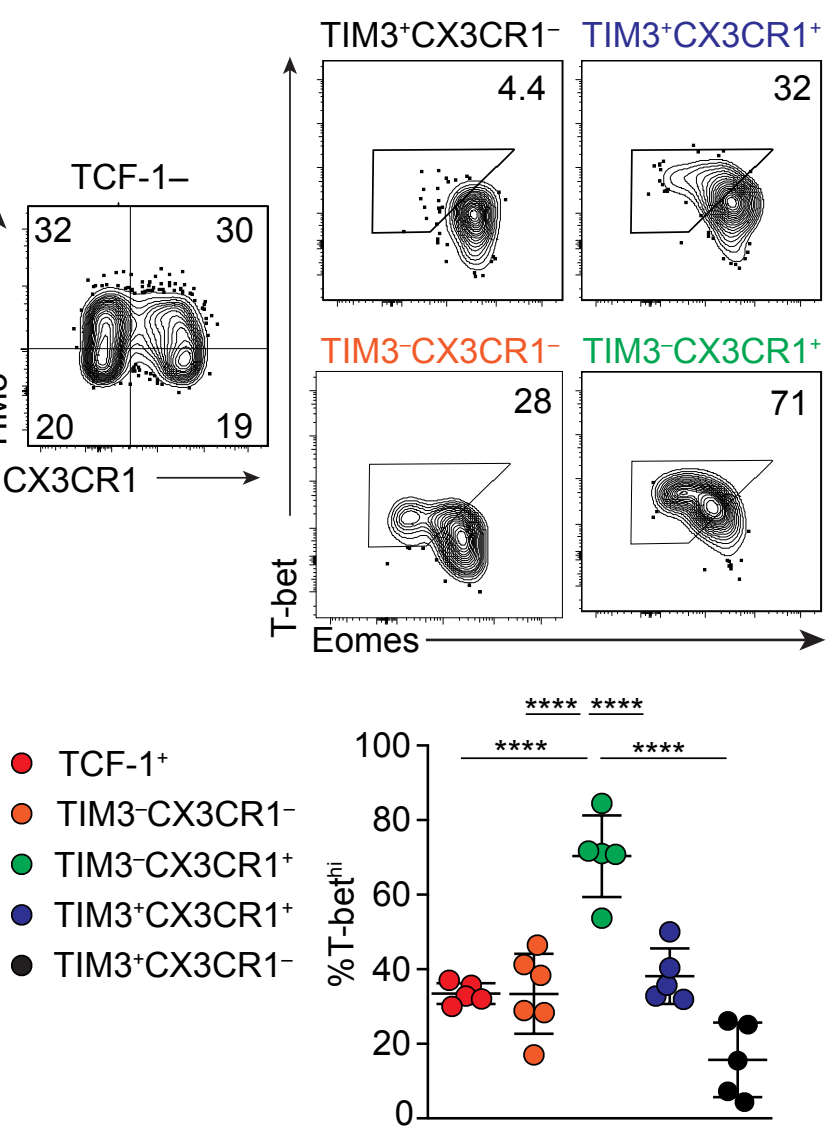
Figure 3

A TCF-1- gp33-tetramer ${ }^{+}$CD8 T cells

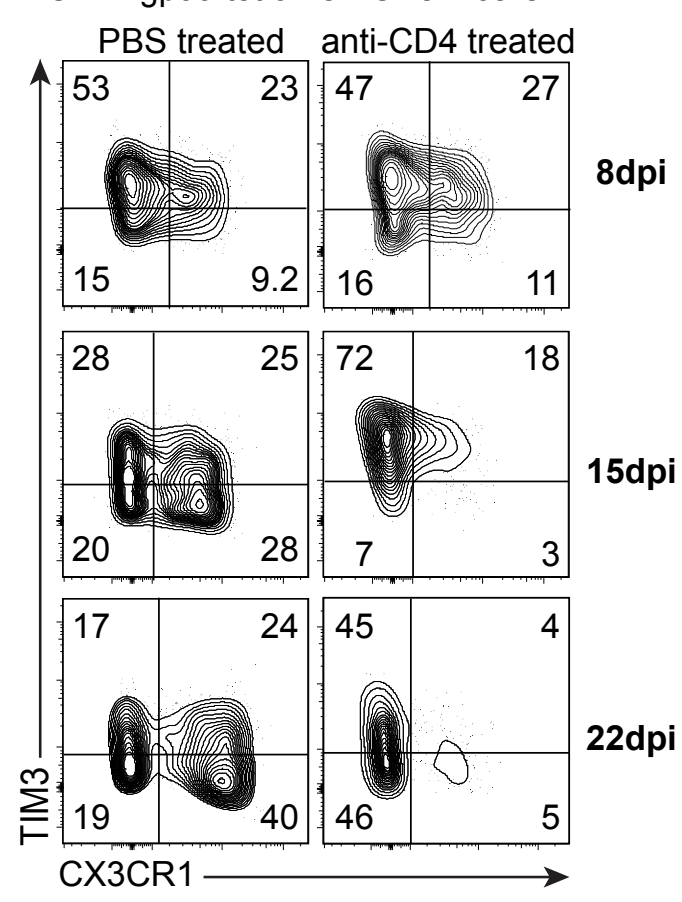

B

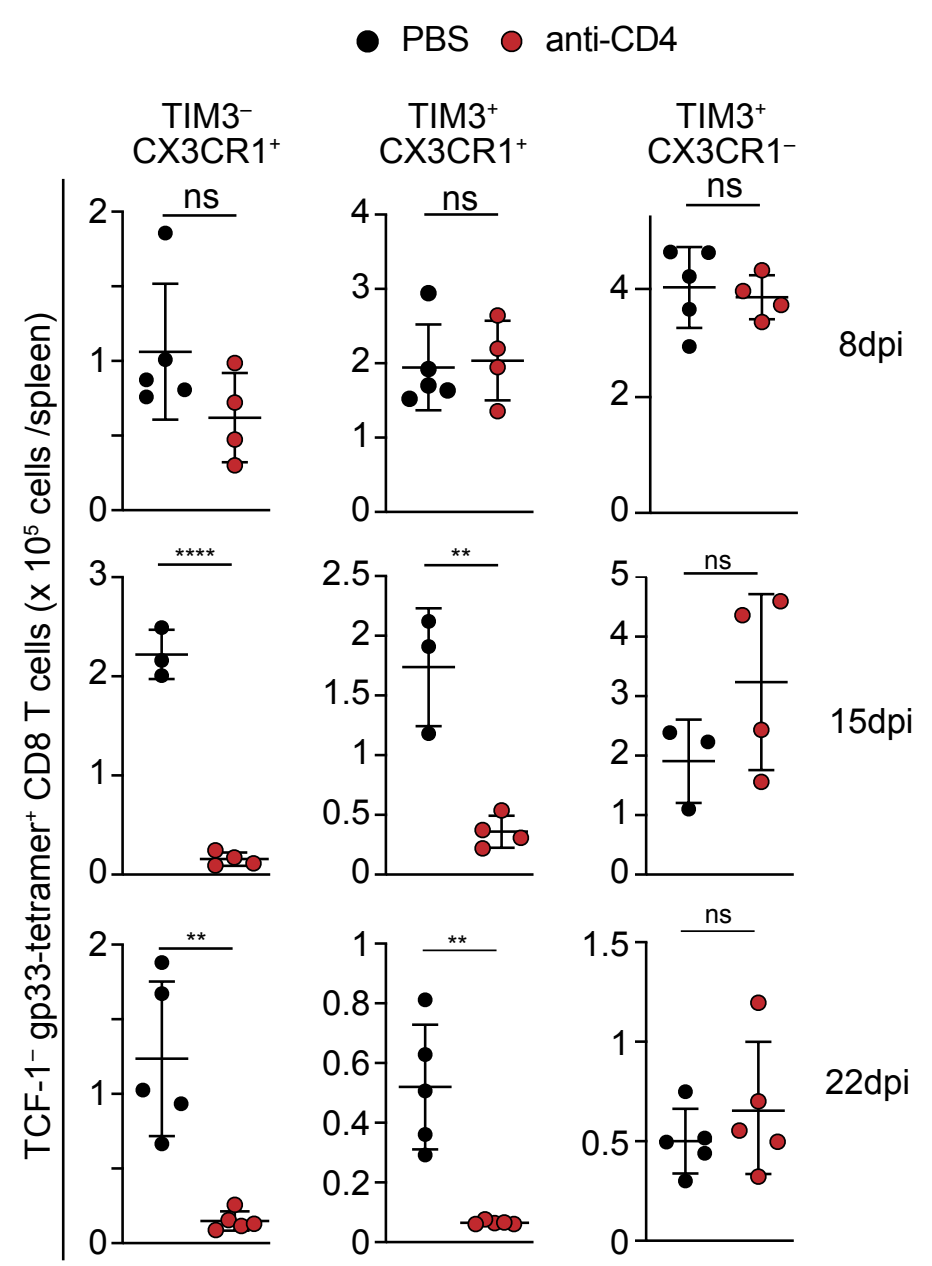

C

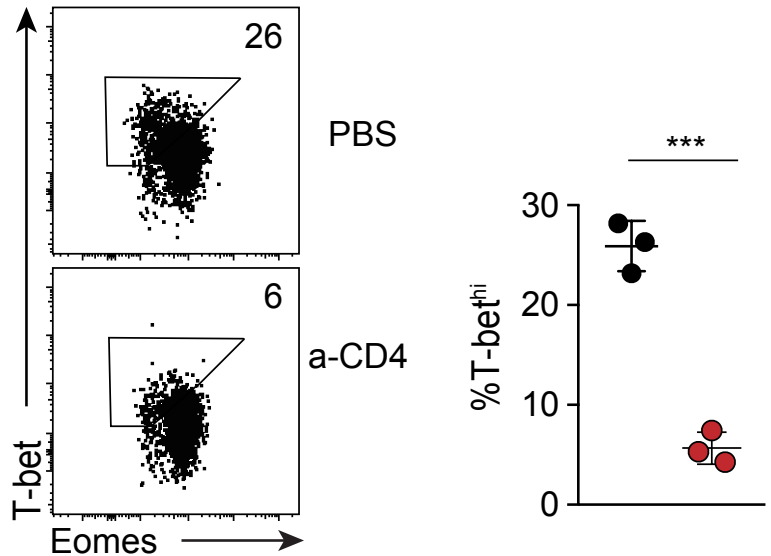

D

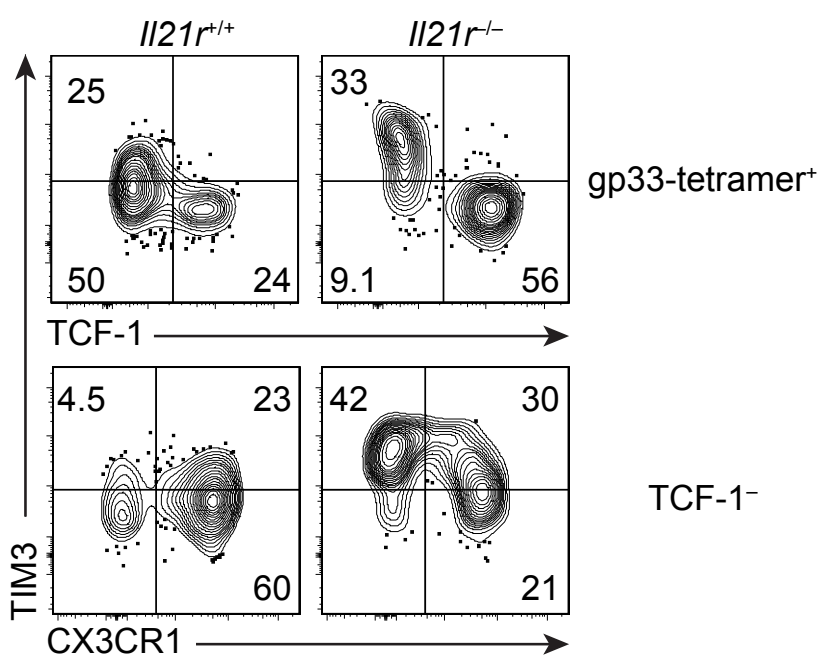

E
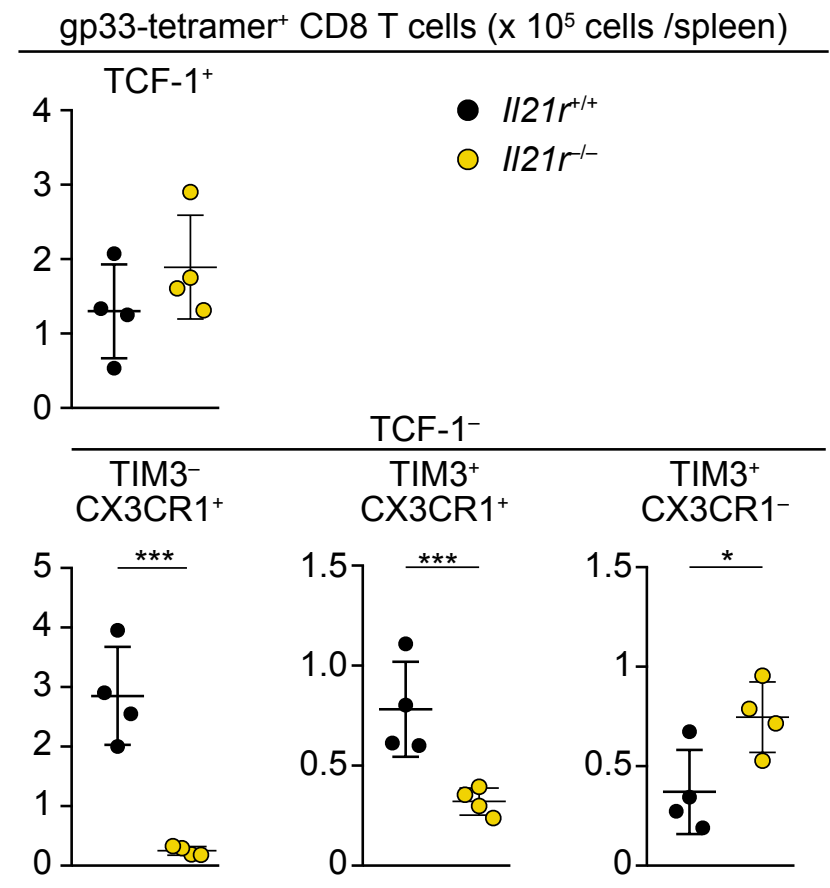
Figure 4

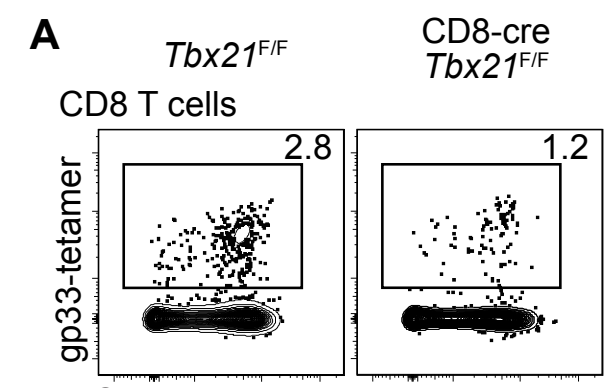

CD44

gp33-tetramer ${ }^{+}$

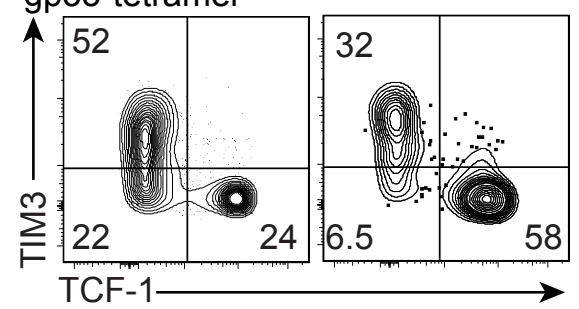

TCF-1-

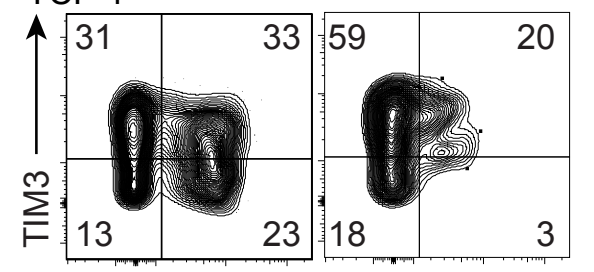

CX3CR1

D $\begin{array}{ll}\text { Eomes }^{\mathrm{F} / \mathrm{F}} & \text { CD8-cre } \\ \text { Eomes }^{\mathrm{F} / \mathrm{F}}\end{array}$

CD8 T cells

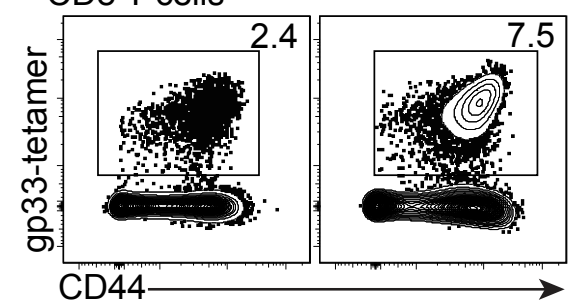

gp33-tetramer ${ }^{+}$

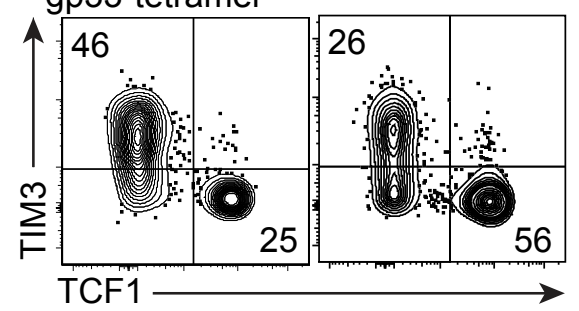

TCF-1-

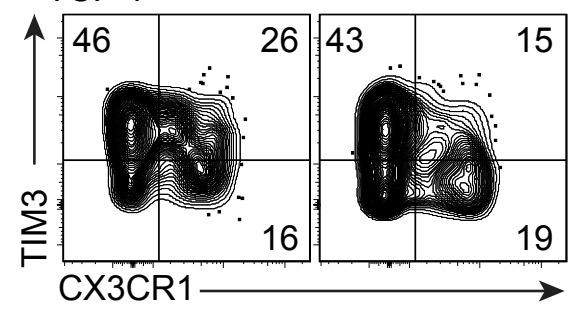

B

- $T b \times 21^{\mathrm{F} / \mathrm{F}} \bigcirc \mathrm{CD} 8-\mathrm{cre} T b \times 21^{\mathrm{F} / \mathrm{F}}$
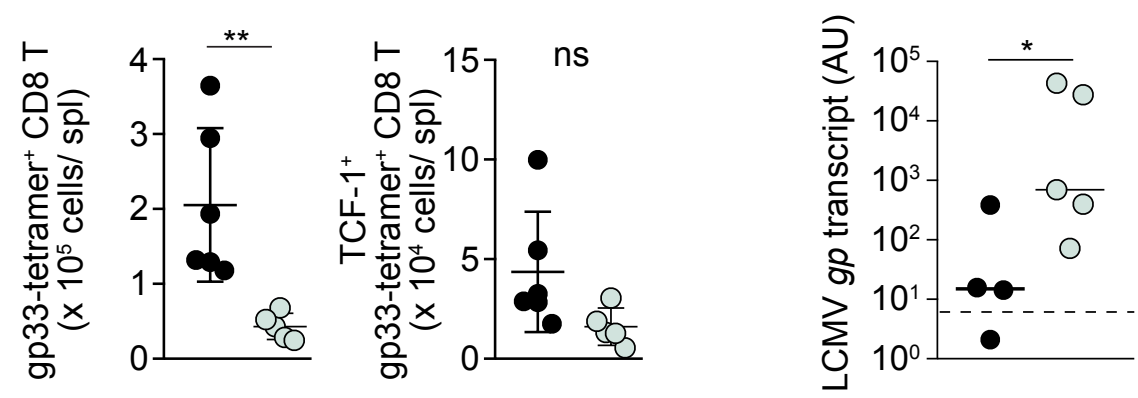

E
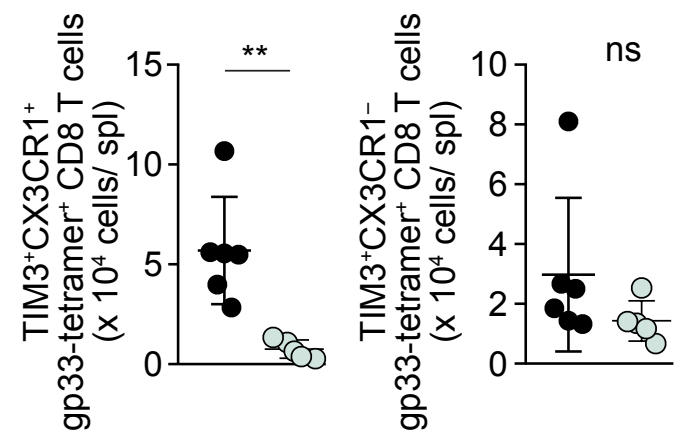

F
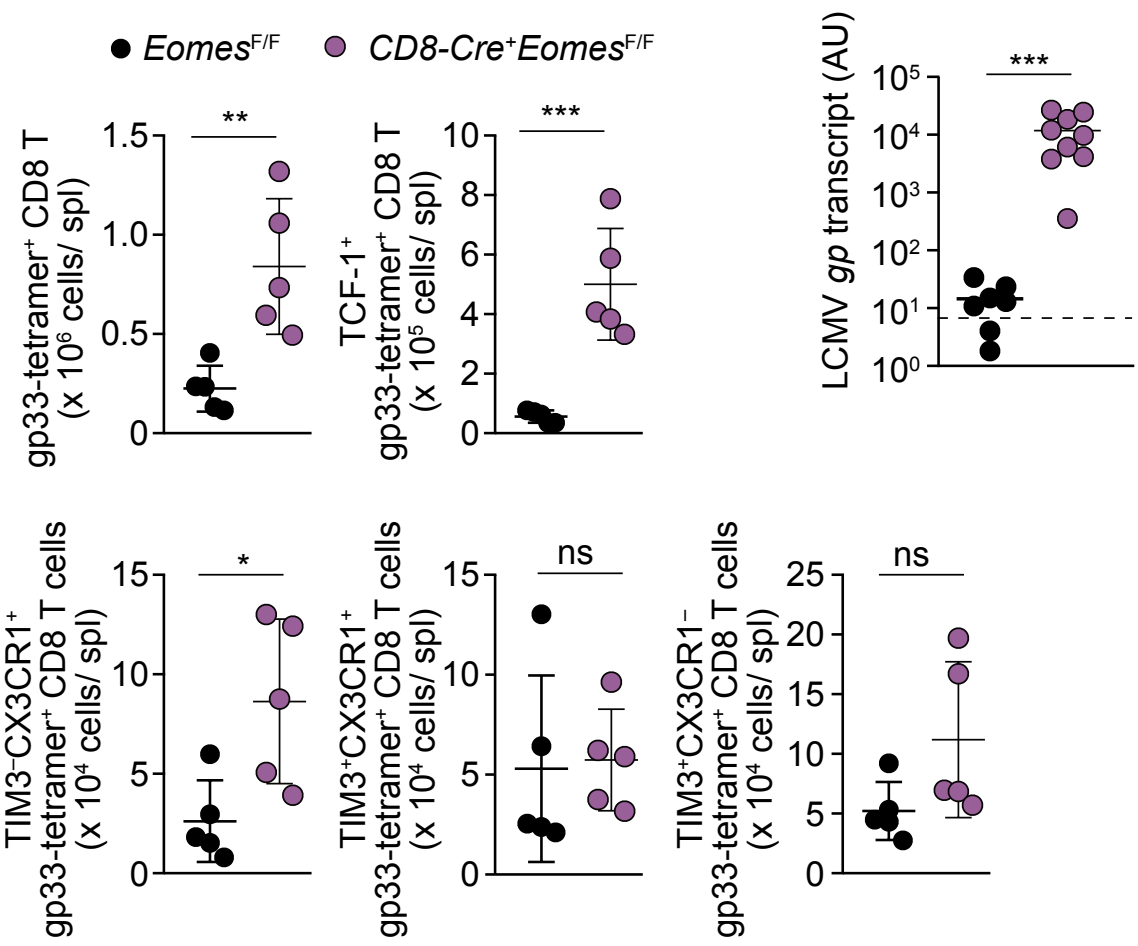
A

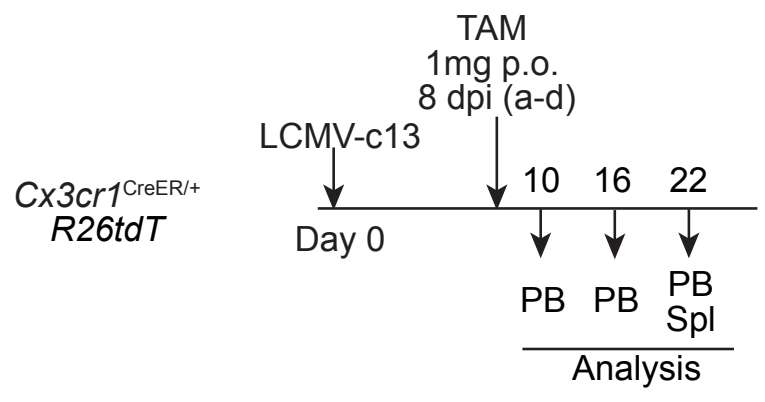

C

22 dpi Spleen

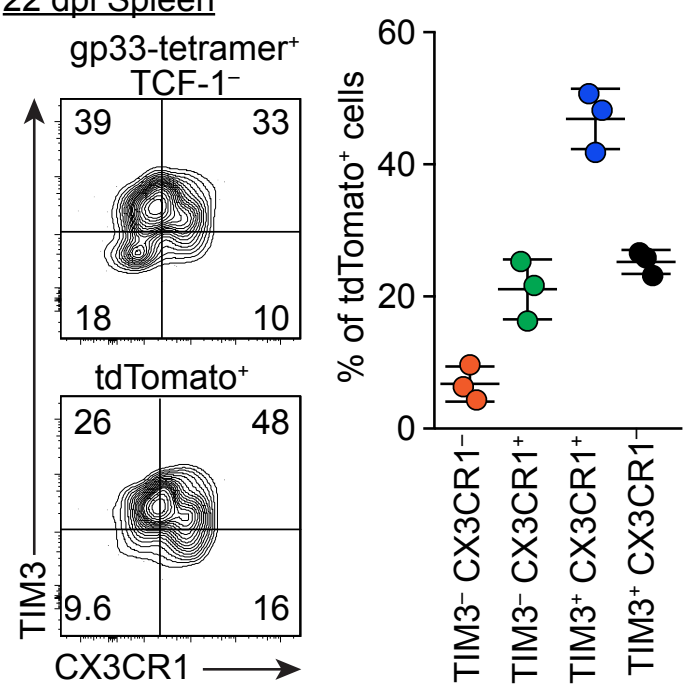

B

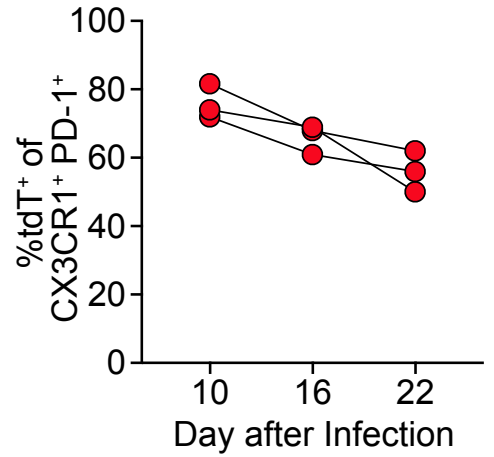

E
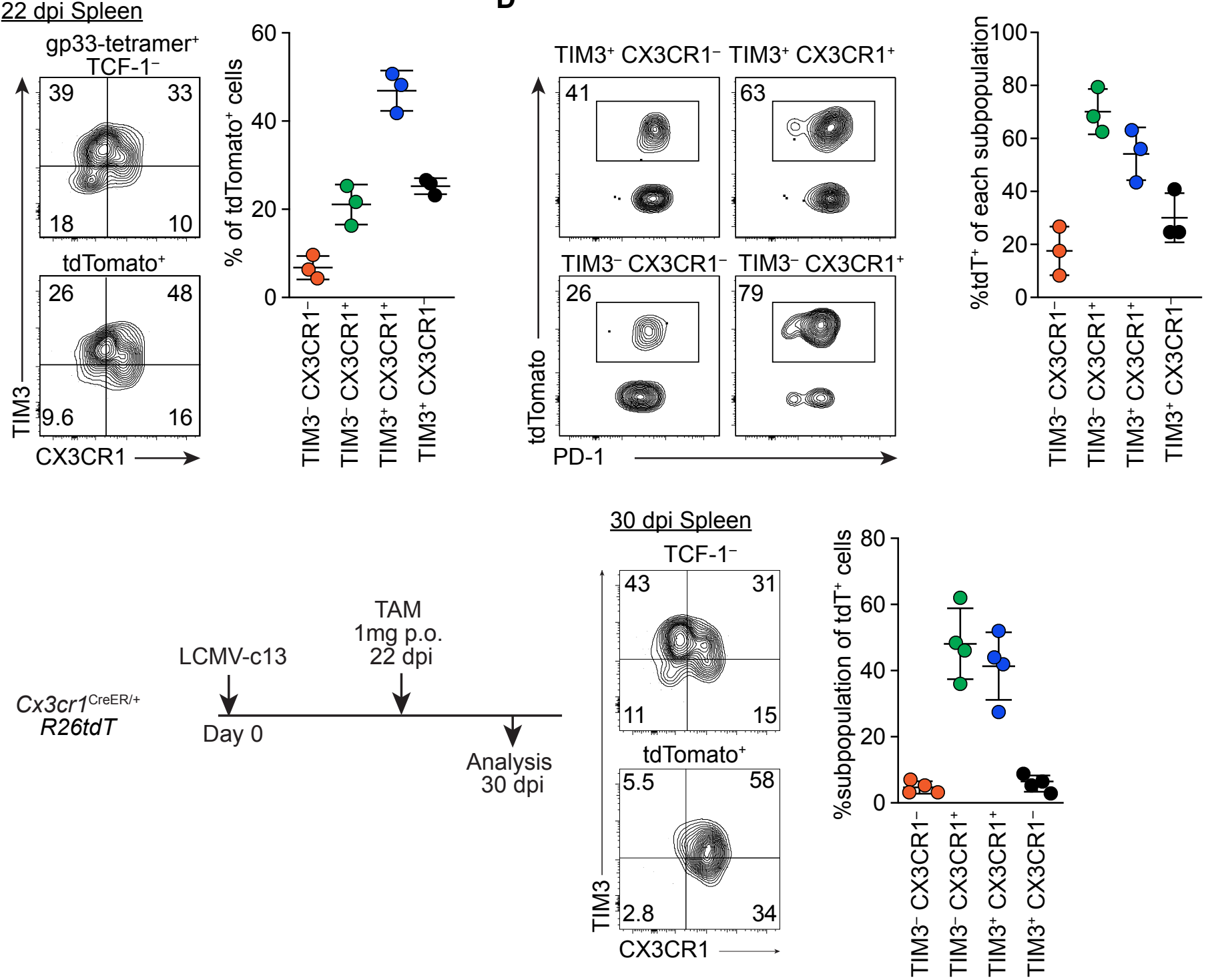


\section{Supplementary Figure 1}

A

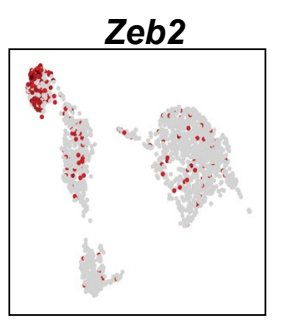

Prdm1

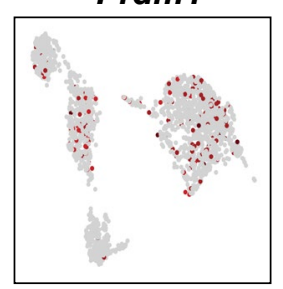

Cd244

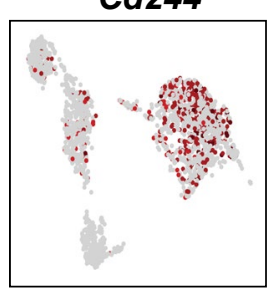

C

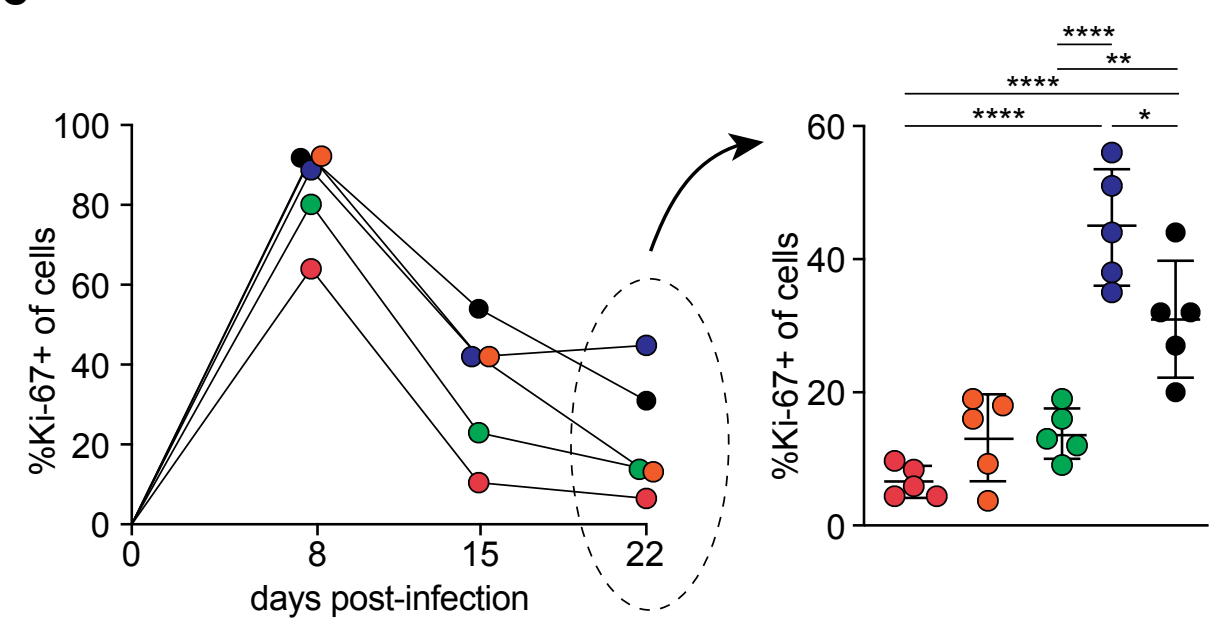

$T b \times 21$

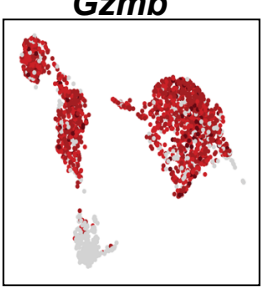

Tox

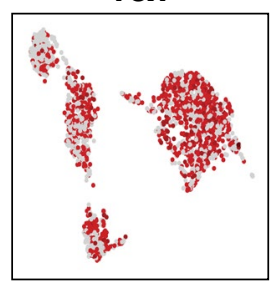

Pdcd1 (PD-1)

fit?

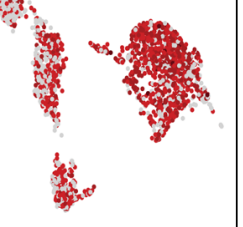

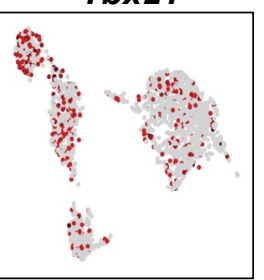

Eomes

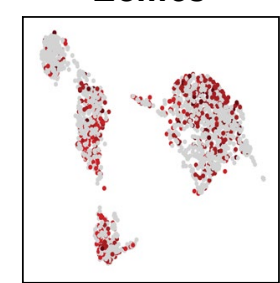

Slamf6

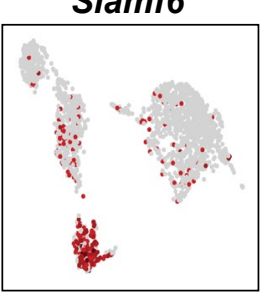

B

TCF-1-

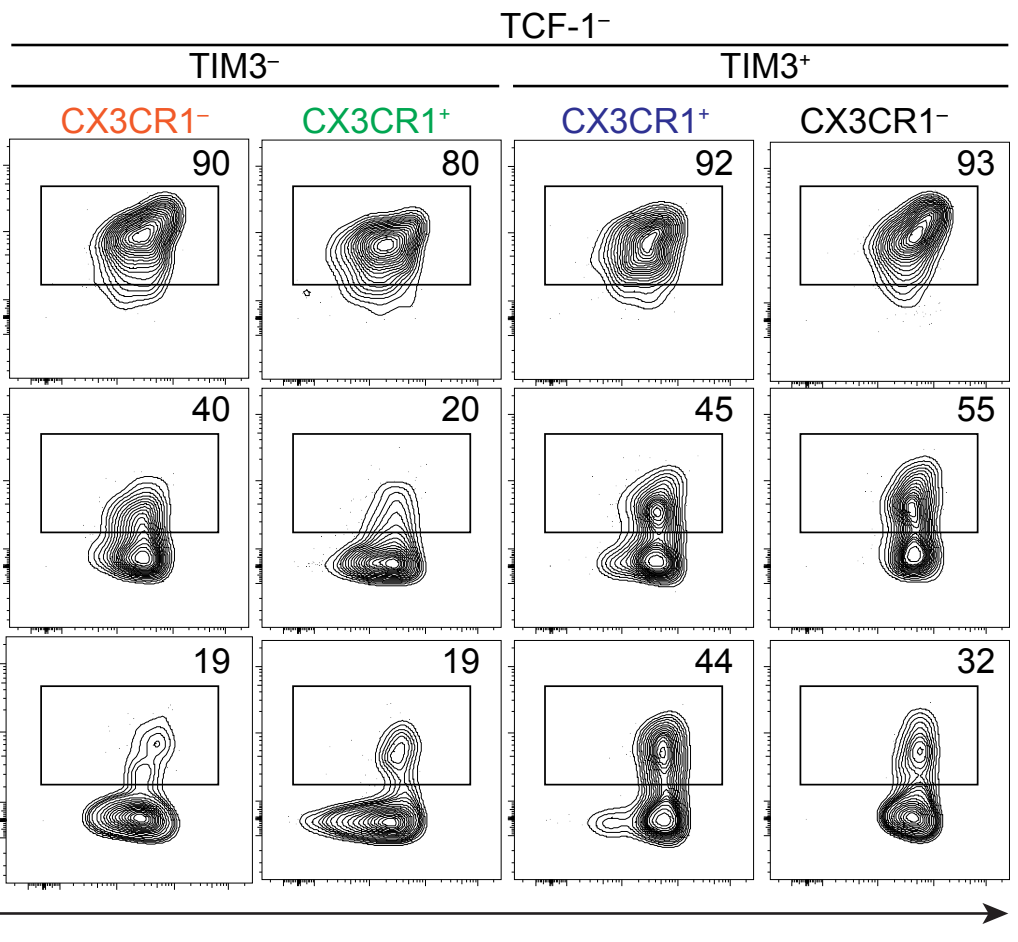

D

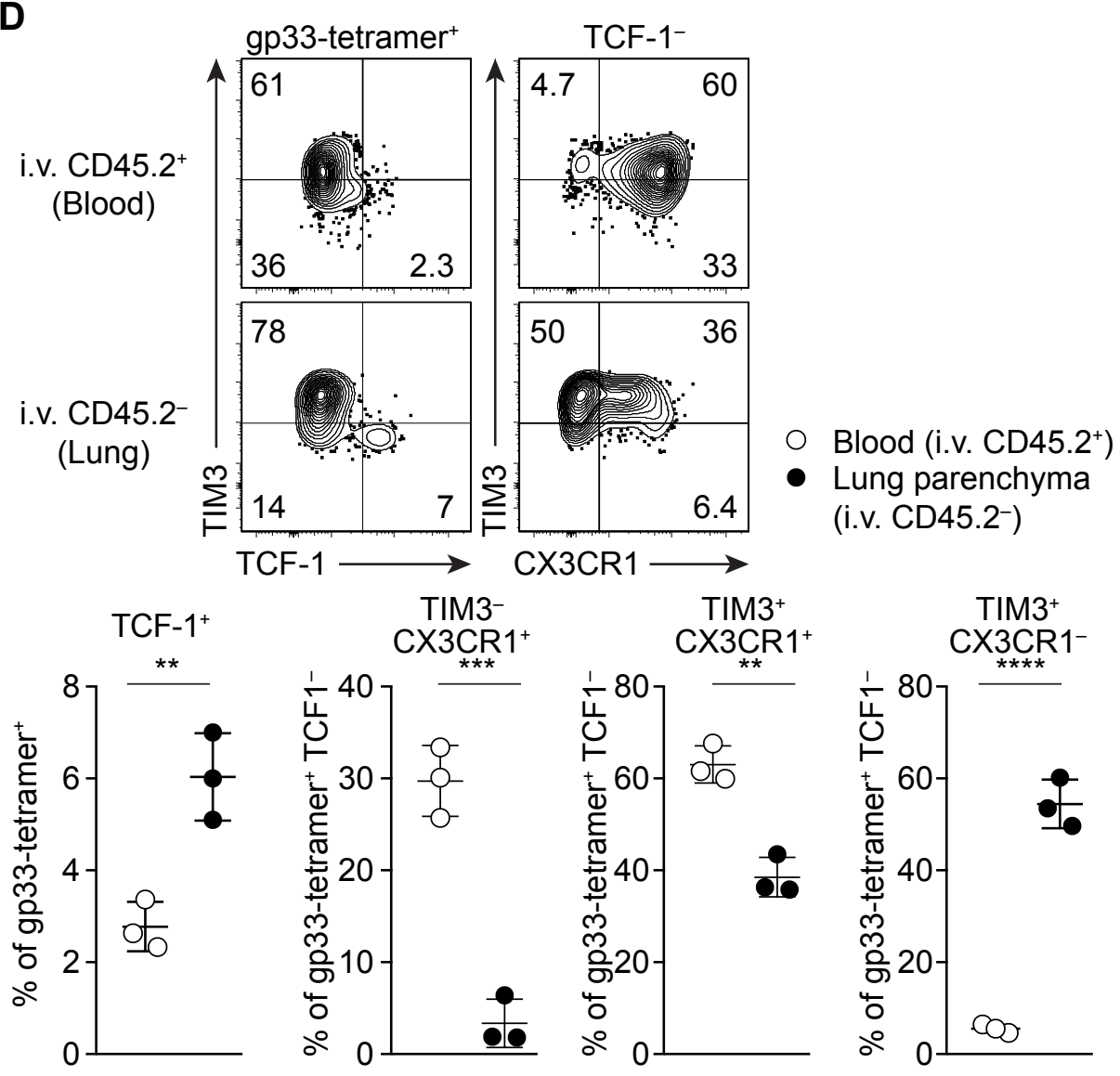


Supplementary Figure 2

Day 19 MC38 Tumor
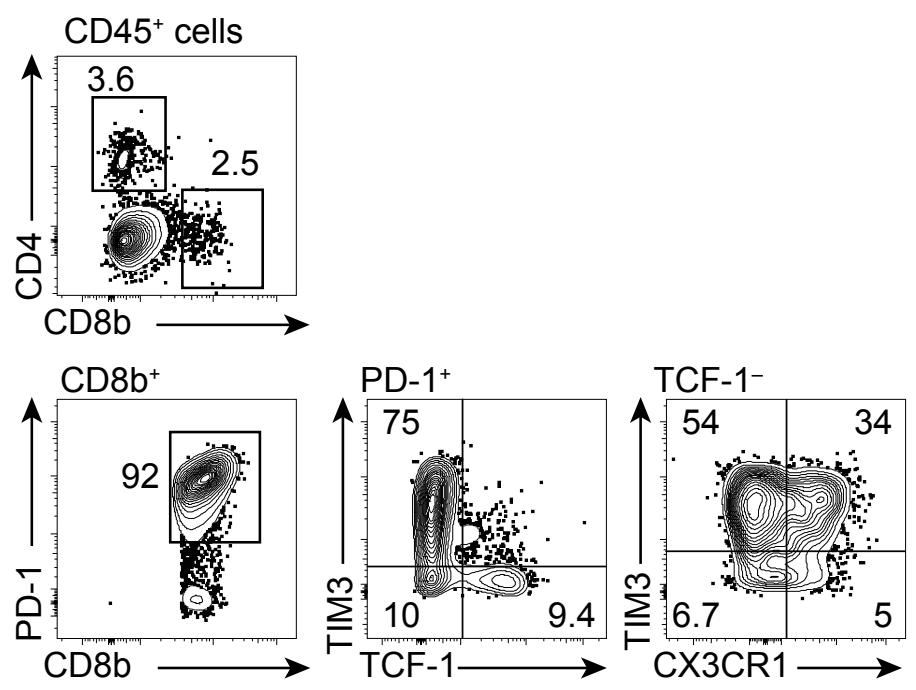

Day 8 E.G7 Tumor

in Prdm1-YFP mice
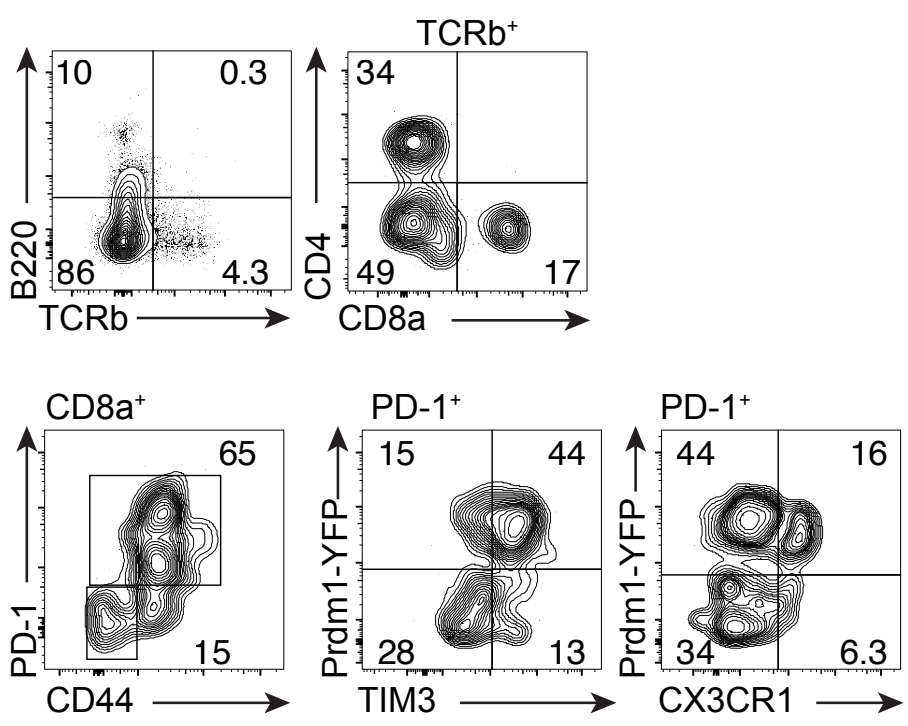


\section{Supplementary Figure 3}

A

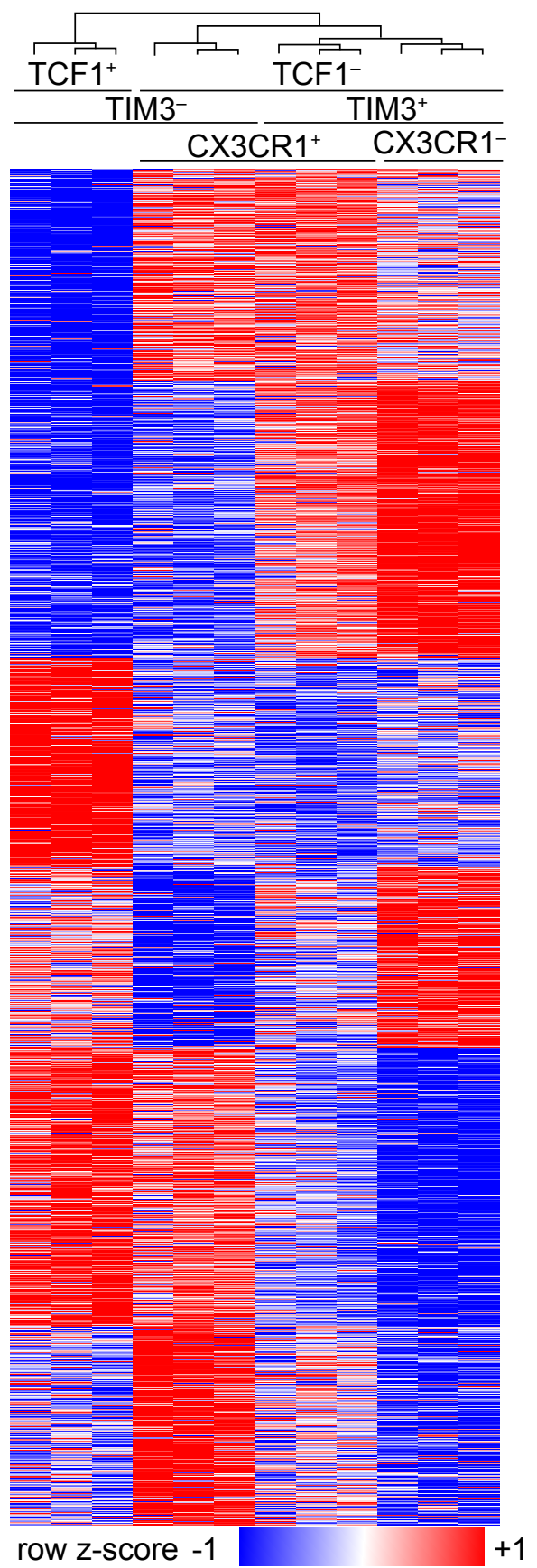

\begin{tabular}{|c|c|c|c|c|}
\hline & TC & $\begin{array}{c}\text { TCF-1- }^{-} \\
\text {TIM3- CX3CR1 }^{+}\end{array}$ & $\begin{array}{c}\text { TCF-1- } \\
\text { TIM3 }^{+} \text {CX3CR1 }\end{array}$ & $\begin{array}{c}\text { TCF-1- } \\
\text { TIM3 }^{+} \text {CX3CR1- }\end{array}$ \\
\hline TCF-1+ & & $\begin{array}{l}\text { Cx3cr1, S1pr5, } \\
\text { Itgam, Adgrg1, } \\
\text { Chn2, Lrcc75b, } \\
\text { Muc20, Ggt1, } \\
\text { Adamts14, Lat, Sell, } \\
\text { Btla, } \\
\text { A630023P12Rik, } \\
\text { Crtam, Myb }\end{array}$ & $\begin{array}{l}\text { Ccl3, Chn2, Adgrg1, } \\
\text { Havcr2, Cx3cr1, } \\
\text { Itgam, Plekhh3, } \\
\text { Adamts14, Muc20, } \\
\text { Prr11, Entpd1, } \\
\text { Frmd4b, Sgo1, } \\
\text { C1qtnf6, Neurl1b }\end{array}$ & $\begin{array}{l}\text { Chn2, Plekhh3, } \\
\text { Ccl3, Adgrg1, } \\
\text { Frmd4b, Havcr2, } \\
\text { Muc20, Fam129b, } \\
\text { Kif20a, Ccna2, } \\
\text { Ccnf, Prr11, } \\
\text { Fam83d, Kif22, } \\
\text { Spag5 }\end{array}$ \\
\hline $\begin{array}{c}\text { TCF-1- } \\
\text { TIM3- }^{-} \\
\text {CX3CR1 }^{+}\end{array}$ & $\begin{array}{l}\text { Nsg2, Tnfsf8, } \\
\text { Slamf6, Cd22, Ccr6, } \\
\text { Myb, Crtam, } \\
\text { A630023P12Rik, } \\
\text { Btla, Sell, Rflnb, } \\
\text { Ankrd13b, } \\
\text { 1700019D03Rik, } \\
\text { Aff3, Xcl1 }\end{array}$ & & $\begin{array}{l}\text { Slc16a10. Rgs16, } \\
\text { Ccl4, Tnfrsf9, } \\
\text { Havcr2, Ncapg, } \\
\text { Ska3, Ccnb1, } \\
\text { Top2a, Ncaph, Ttk, } \\
\text { Egr1, Diaph3, } \\
\text { Phf19, Stil }\end{array}$ & $\begin{array}{l}\text { Slc16a10, Ncapg, } \\
\text { Tpi1, Marcksl1, } \\
\text { Tnfrsf9, Rrm1, } \\
\text { Smyd5, Ncapg2, } \\
\text { Rad51, Aurka, } \\
\text { Nup133, Arhgap19, } \\
\text { Rgs16, Top2a, } \\
\text { Mcm5 }\end{array}$ \\
\hline $\begin{array}{c}\text { TCF-1- } \\
\text { TIM3 }^{+} \\
\text {CX3CR1 }^{+}\end{array}$ & $\begin{array}{l}\text { P2rx7, Id3, Tnfsf8, } \\
\text { Samd3, Slamf6, } \\
\text { Cpne3, Sell, Crtam, } \\
\text { Tcf7, Zhx2, } \\
\text { A630023P12Rik, } \\
\text { Nt5e, Evl,,, } \\
\text { A630014C17Rik, } \\
\text { Rflnb }\end{array}$ & $\begin{array}{l}\text { Slco3a1, KIhl6, } \\
\text { Tcp11/2, Itgb1, } \\
\text { Mylip, Cpne3, } \\
\text { Emb, B3gnt5, } \\
\text { Nr1d2, KIhl24, } \\
\text { Samd3, Trp53inp1, } \\
\text { Kbtbd11, Dtx4 }\end{array}$ & & $\begin{array}{l}\text { Osgin1, Marcksl1. } \\
\text { Pfgfrn, Thop1, } \\
\text { Dnph1, Mthfd1, } \\
\text { Gart, Pno1, } \\
\text { Camsap2, Ifrd2, } \\
\text { C1qbp, Hsp90aa1, } \\
\text { Aunip, Aldh7a1, } \\
\text { Ipo5 }\end{array}$ \\
\hline $\begin{array}{c}\text { TCF-1- } \\
\text { TIM3 }^{+} \\
\text {CX3CR1- }^{-}\end{array}$ & $\begin{array}{l}\text { Id3, Nsg2, Tcf7, } \\
\text { Acss1, Slamf6, } \\
\text { Samd3, Nt5e, } \\
\text { Ms4a4c, Scml4, } \\
\text { Klhl6, Parp8, } \\
\text { Sh2b3, Sh3bp5, } \\
\text { Bcl6, Evl }\end{array}$ & $\begin{array}{l}\text { Cx3cr1, Acss1, } \\
\text { II18rap, KIhl6, Zeb2, } \\
\text { Hid1, Nr1d2, Neat1, } \\
\text { Klrd1, Fcgr2b, } \\
\text { Fbxl20, Ccl5, } \\
\text { Tcp11/2, Itgb1, } \\
\text { Rap1gap2 }\end{array}$ & $\begin{array}{l}\text { Cx3cr1, Itgam, Chit1 } \\
\text { Adgrb2, Lpin1, } \\
\text { Cmklr1, Btnl5-ps, } \\
\text { Ccl5, Tmem37, } \\
\text { Zeb2, Prr5I, Nipal3, } \\
\text { Mirt1, Miat, F2rl2 }\end{array}$ & \\
\hline
\end{tabular}


Supplementary Figure 4

A

8dpi

PBS treated anti-CD4 treated

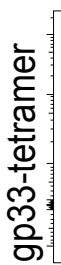

4.8

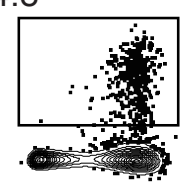

CD44
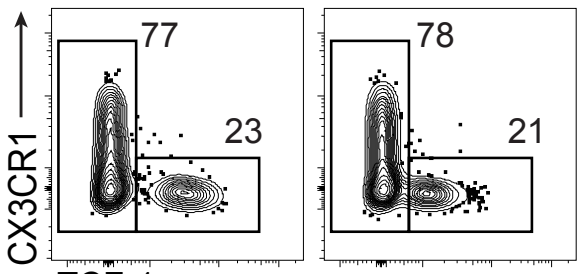

d15 dpi

d22 dpi

PBS treated anti-CD4 treated PBS treated anti-CD4 treated

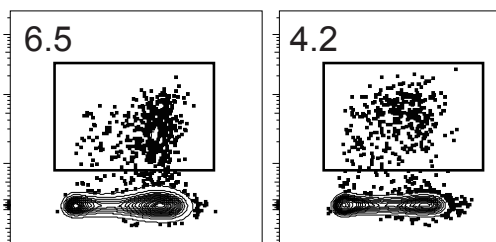

4.1

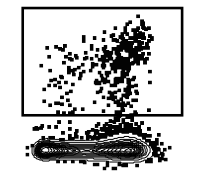

2.7

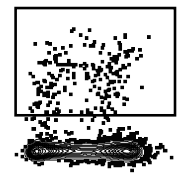

TCF-1
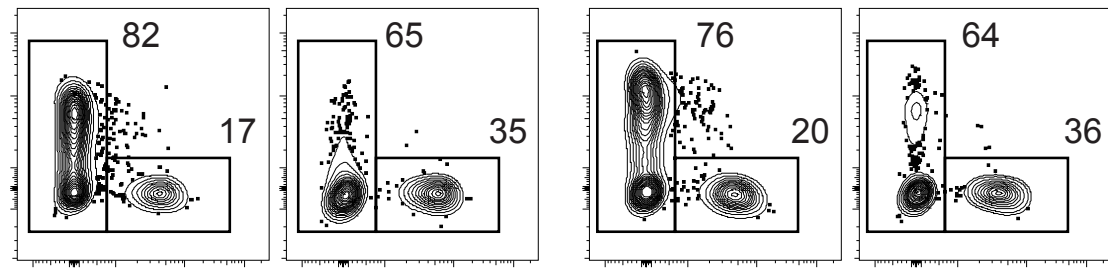

B

- PBS 0 anti-CD4
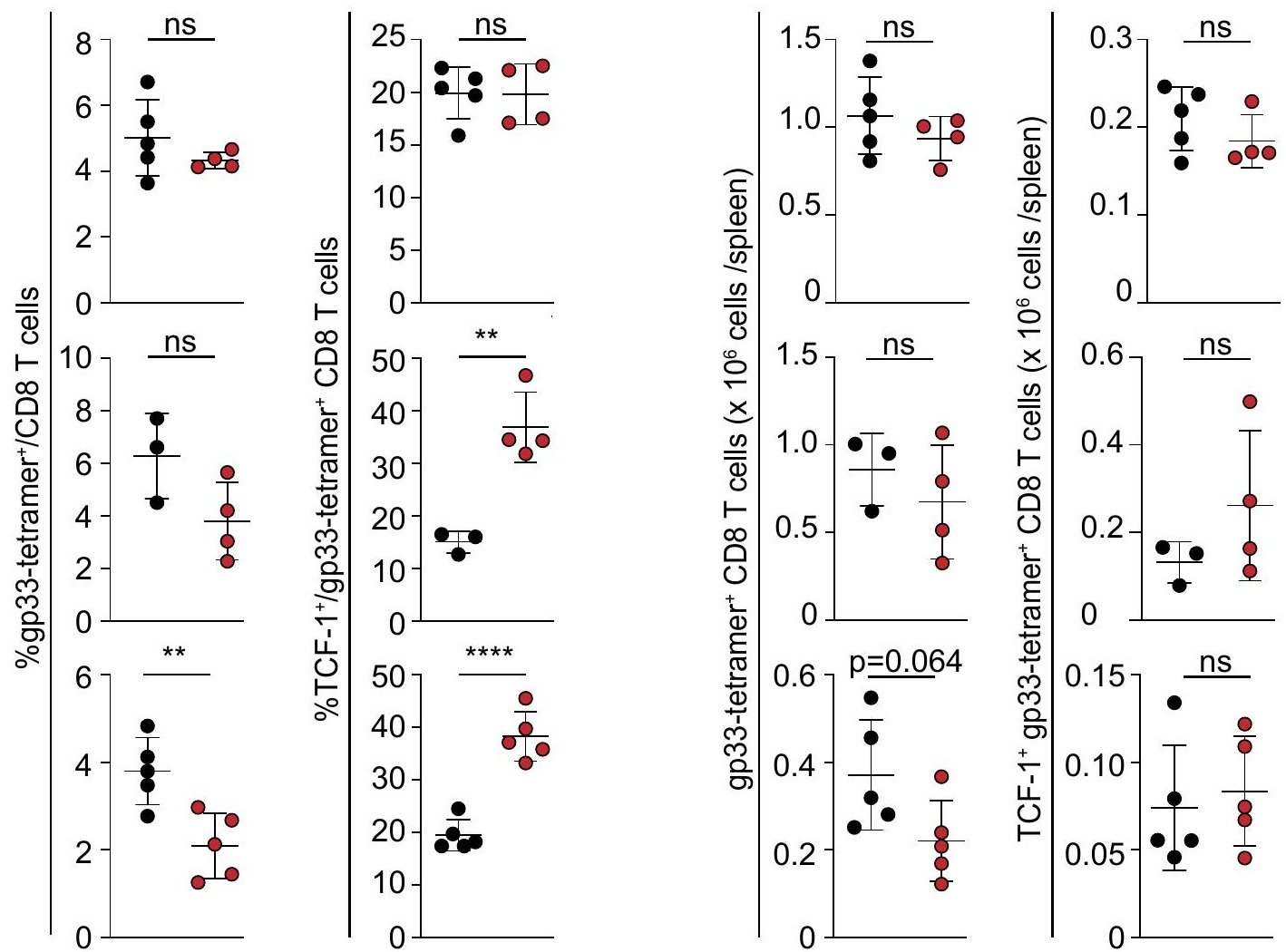

d8 dpi

d15 dpi

d22 dpi 
Supplementary Figure 5

A

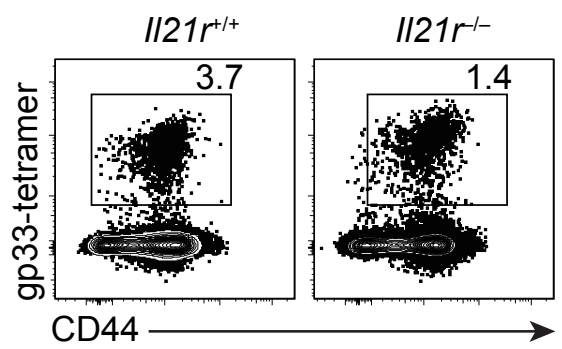

B

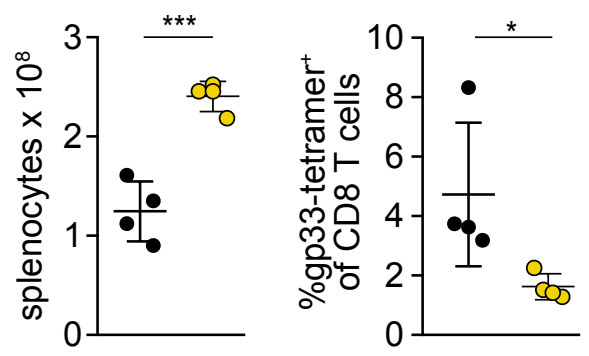

B6

muMT

total splenocytes

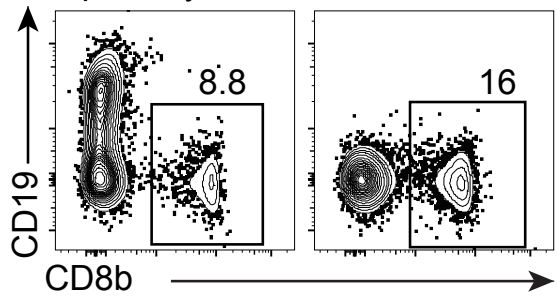

TCF-1- gp33-tetramer ${ }^{+} \mathrm{CD}^{+}{ }^{+} \mathrm{T}$ cells

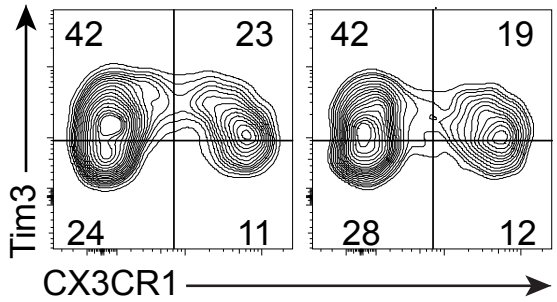

- $/ 121 r^{+++}$

O $/ 121 r^{-1-}$

CD8 T cells

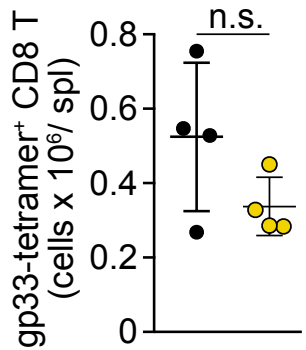

D

- B6

○ $\mu \mathrm{MT}^{-1-}$
Tim3-

CX3CR $1^{+}$
$\mathrm{Tim}^{+}$

CX3CR ${ }^{+}$
Tim $^{+}$

CX3CR1-

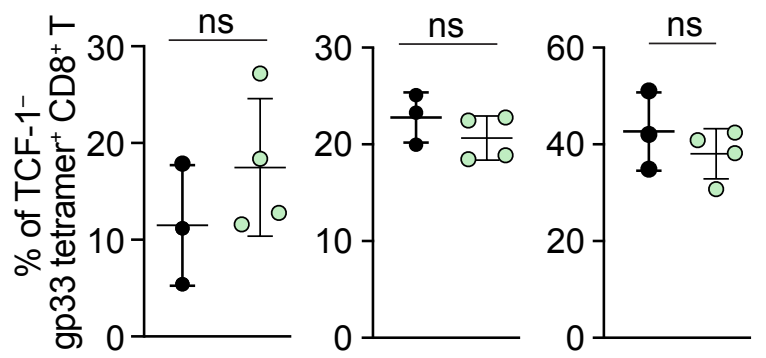


A
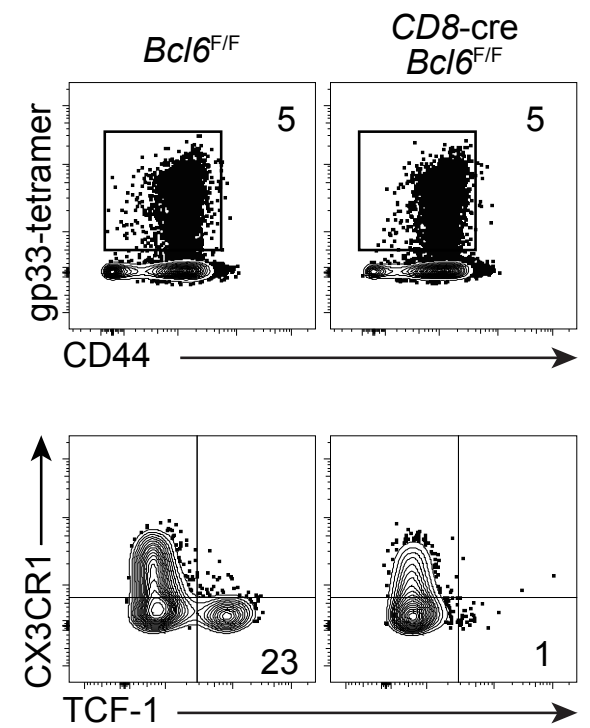

B
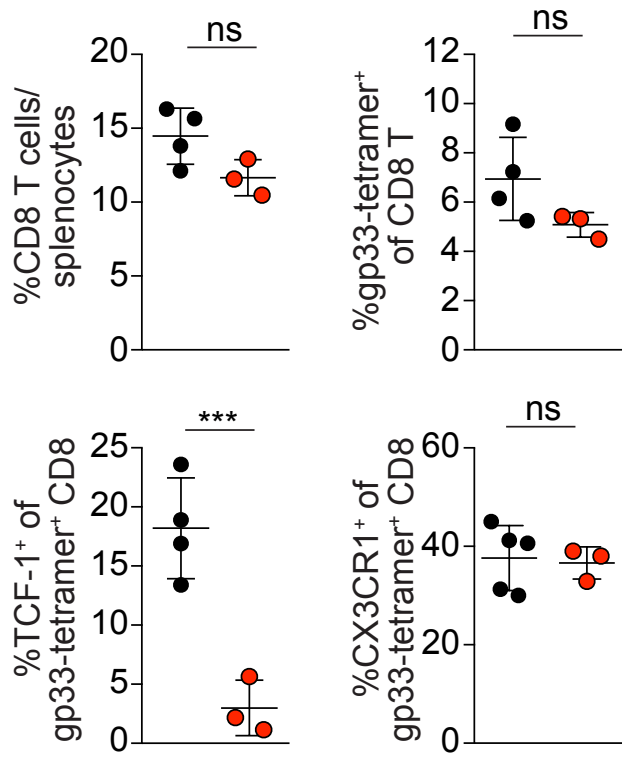
Supplementary Figure 7

A

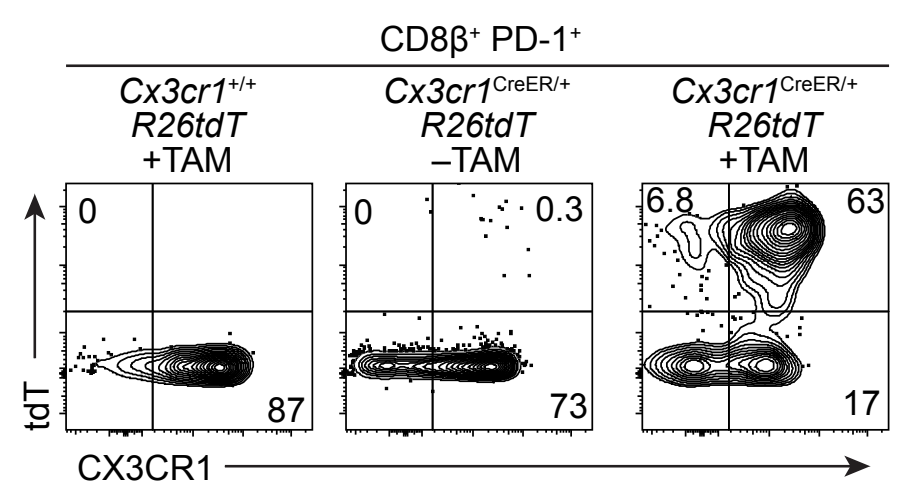

B
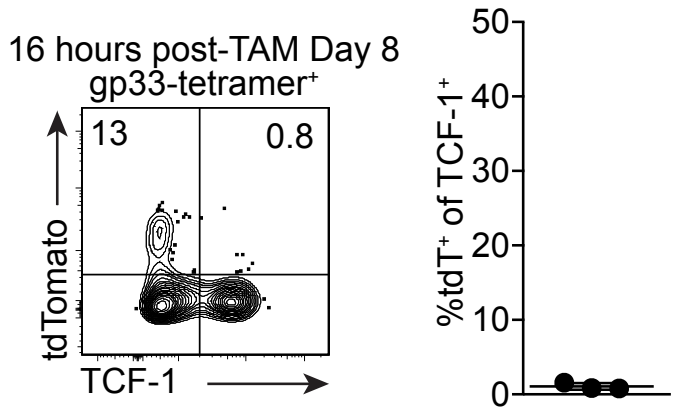

CD8 T cells
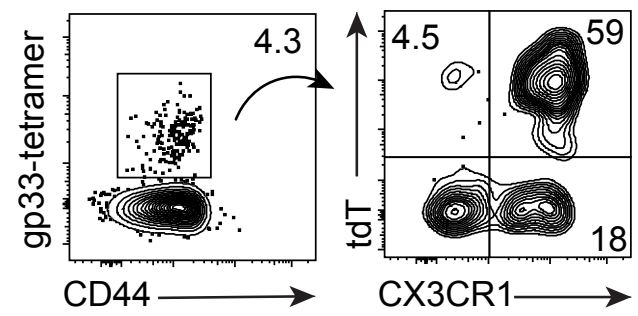